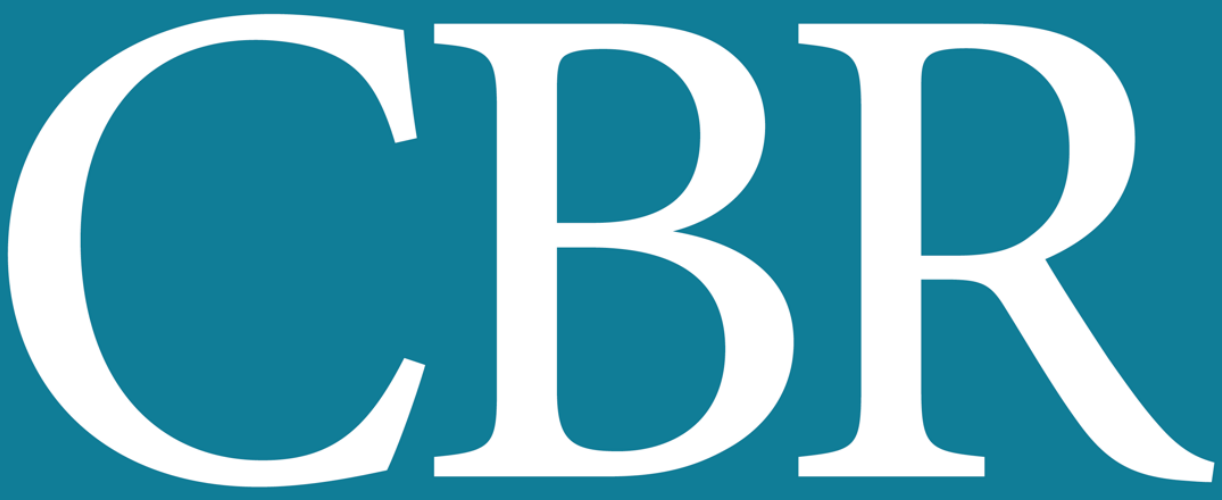

INTERNATIONAL JOURNAL OF CANCER AND BIOMEDICAL RESEARCH

https://jcbr.journals.ekb.eg

Editor-in-chief

Prof. Mohamed Labib Salem, PhD

Caspase-3 activities and androgen receptor expression in rats' testis during the early biochemical and histopathological changes induced by a carcinogen, Diethylnitrosamine: role of probiotics and pyridazine derivatives

Ahmed A. Morsi, Sahar B. Ahmed, Neveen M. Saleh, Rania A.H.

Abd El-Aal, Tamer El Malah and Asmaa M. Elsayed 


\title{
Caspase-3 activities and androgen receptor expression in rats' testis during the early biochemical and histopathological changes induced by a carcinogen, Diethylnitrosamine: role of problotics and pyridazine derivatives
}

\author{
Ahmed A. Morsi' ${ }^{1}$, Sahar B. Ahmed², Neveen M. Saleh ${ }^{3}$, Rania A.H. Abd El-Aal', Tamer El Malah ${ }^{5}$ and Asmaa \\ M. Elsayed ${ }^{1}$ \\ ${ }^{1}$ Department of Histology and Cell Biology, Faculty of Medicine, Fayoum University, Fayoum, Egypt \\ 2Division of Biochemistry, National Organization for Drug Control and Research (NODCAR), Giza, Egypt \\ ${ }^{3}$ Microbiology Department, National Organization for Drug Control and Research (NODCAR), Giza, Egypt \\ ${ }^{4}$ Developmental Pharmacology Department, National Organization for Drug Control and Research (NODCAR), Giza, Egypt \\ ${ }^{5}$ Photochemistry Department, Chemical Industries Research Division, National Research Centre, Cairo, Egypt
}

III ABSTRACT

Background: Diethylnitrosamine (DENA) is a common environmental toxicant with a well-known hepatocarcinogenic potential. Aim: The current study aimed to: 1 ) investigate the carcinogenic toxicity of DENA on the rats' testis, 2) to elucidate the role of caspase-3 activities and androgen receptors (AR) in this toxicity, and 3) to assess the effect of treatment with Lactobacillus casei (LAB) and 3-methylsulfanyl4,6-diphenyl-pyridazine (MDP) on testicular tumorigenesis. Material and Methods: Sixty Sprague-Dawley albino rats were divided into 6 groups; control, DENA-alone, DENA+MDP, DENA+LAB, DENA+DOX (Doxorubicin) and DENA+DOX+MDP. In all experimental animals, DENA was injected intraperitoneal (i.p) $(55 \mathrm{mg} / \mathrm{kg})$ twice weekly for 6 weeks. MDP (10 mg/kg, ip), LAB (1.5 x 109 $\mathrm{CFU} / \mathrm{kg}$, oral) and DOX (10 mg/kg, ip) were administered twice weekly for the following 4 weeks. Serum testosterone, anti-mullerian hormone, alphafetoprotein, tumor necrosis factor, nitric oxide, glutathione peroxidase, and sperm analysis were determined. Histopathological evaluation of the testis was done. AR and caspase- 3 activities were detected by immunohistochemistry. Result: The DENA-alone-treated animals showed disturbed biochemical assays and marked tubular degenerative changes, in addition to notable Leydig cell hyperplasia (LCH) in the histological findings. MDP, LAB, DOX reversed the biochemical changes with less extent in DOX treatment. No further improvement was noted in the tubular histoarchitecture in DOX-treated groups meanwhile, LAB treatment restored LCH with a partial effect in MDP treatment. Conclusion: DENA induced ARimmunopositive Leydig cell hyperplastic changes, in addition to spermatogenic cytotoxicity with increased tubular caspase- 3 activities. LAB and MDP reversed biochemical changes and had a curative potential on the testis with a partial antiproliferative effect for MDP.

Keywords: Androgen receptors, Caspase-3, Diethylnitrosamine, Lactobacillus casei, 3-Methylsulfanyl-4,6-diphenyl-pyridazine, Pyridazine derivatives, Testis

Editor-in-Chief: Prof. M.L. Salem, PhD - Article DOI: 10.21608/jcbr.2021.2104-1207

\section{ARTICLE INFO}

Article history

Received: April 27, 2021

Revised: July 7, 2021

Accepted: August 3, 2021

Correspondence to:

Dr Rania A.H. Abd El-Aa Developmental Pharmacology Department, National Organization for Drug Control and Research (NODCAR), Giza, Egypt Tel. 01001044350 Email: raniaawad350@yahoo.com

Copyright

(02021 Ahmed A. Morsi, Sahar B. Ahmed, Neveen M. Saleh, Rania A.H. Abd El-Aal, Tamer El Malah and Asmaa M. Elsayed. This is an Open Access article distributed under the Creative Commons Attribution License, which permits unrestricted use, distribution, and reproduction in any medium, provided the original work is properly cited.

\section{INTRODUCTION}

Environmental contamination of food products is a major health problem that constitutes a global concern or threat to human biosafety (Thompson and Darwish, 2019). Diethylnitrosamine (DENA) is a well-known environmental toxicant present all around; in water, food, air and soil with a daily intake as high as $0.03 \mu \mathrm{g} / \mathrm{kg} /$ day from all sources as reported by the World Health Organization (WHO, 2002). DENA is a potent chemical hepatocarcinogenic agent that exerts its carcinogenic effect through induction of oxidative stress, the release of reactive oxygen 
species (ROS) and lipid peroxidation (Gronow, 2019).

Androgen receptors (AR) are necessary for Leydig cells development with subsequent normal testicular function in adults. There is a great suggestion that disruption of androgen/AR signalling can initiate and stimulate testicular tumorigenesis and Leydig cell hyperplasia, in particular under the effect of luteinizing hormone (LH) (O'Shaughnessy et al., 2019). Caspase-3 is one of the executer caspases that is entangled in the induction and amplification of intracellular apoptotic signals and is overexpressed in chemical-induced testicular toxicity indicating germ cell apoptosis (Solano-Gálvez et al., 2018).

Doxorubicin (DOX) has been widely indicated for the treatment of tumors e.g., cancers of the breast, ovary, bladder, and thyroid (JohnsonArbor et al., 2019). The innovation of alternatives will be of greater impact to avoid or minimize the chemotherapy-induced side effects. Pyridazine derivatives demonstrate a broad range of biological and pharmacological activities such as anticancer, antioxidant, antiinflammatory, antiviral, antifungal, anticonvulsant, antidepressant, and antibacterial activities (Popovici et al., 2019). 3Methylsulfanyl-4,6-diphenyl-pyridazine (MDP) is one of the pyridazine derivatives that was newly synthesized from a compound, 4,6diphenyl-2H-pyridazin-3-thione and had an anticancer potential against breast, liver and other cancer cell lines (El Malah et al., 2017). In both animal and human researches, Lactobacillus strains are lactic acid probiotic bacteria (LAB) that have proved various effects including immunomodulation, anti-cancer, antioxidant, and antiulcer activities (Saadat et al., 2019). Therefore, the study strived to: first, investigate the carcinogenic potential and male reproductive toxicity induced by DENA in the testes of albino rats using biochemical, histological and immunohistochemical studies. Secondly, to clarify the encountered role of AR and caspase- 3 activities as well as validating the potential therapeutic efficacy of Lactobacillus casei, pyridazine derivative (MDP), and doxorubicin against these testicular changes.

\section{MATERIALS AND METHODS}

\section{Chemicals and agents}

N-Diethylnitrosamine (DENA): It was purchased from Sigma Aldrich (St. Louis, MO, USA, CAS no. 55-18-5). DENA was dissolved in $4 \mathrm{ml}$ normal saline to obtain a final volume of $27.5 \mathrm{mg} / \mathrm{ml}$.

Doxorubicin hydrochloride: Doxorubicin was supplied from Pharmacia Italia S.P.A. Milan, Italy $(2 \mathrm{mg} / 1 \mathrm{ml})$.

\section{Methylsulfanyl-4,6-diphenyl-pyridazine}

(MDP): MDP was newly synthesized as demonstrated in previous work (El Malah et al., 2017). For animal injection, MDP was dissolved in normal saline to obtain a final volume of 5 $\mathrm{mg} / \mathrm{ml}$.

Lactic acid bacteria strains, culture condition, identification, and preparation: Isolation of $L A B$ was done using the De Man Rogosa Sharpe (MRS) media at $37^{\circ} \mathrm{C}$ for $48 \mathrm{~h}$, as described previously in our publication (Motawee and Saleh, 2016). LAB strains were maintained on MRS broth at $-80^{\circ} \mathrm{C}$ in $20 \%$ glycerol until further use. Bacterial cultures identification was further confirmed using VITEK 2 card aerobic (bioMérieux, Marcy l'Etoile, France) in Animal Health Institute, Giza, Egypt. For rat administration, Lactobacillus casei culture was centrifuged at 2000xg for 5 min, washed with PBS, then frequently filtered, and when its density reached $1.5 \times 10^{9} \mathrm{CFU} / \mathrm{ml}$, it was ready for animal use.

Microbiological analysis for evaluation of the probiotic properties of Lactobacillus casei: Lactobacillus casei isolate was selected in our study to assess their probiotic properties by evaluating its tolerance to temperature, acid, and bile salts as previously described by (Tambekar and Bhutada, 2010) and its antimicrobial activity against pathogens as well as sensitivity profile of antibiotics. Temperature sensitivity was done as described by (Tambekar and Bhutada, 2010 ); MRS broth was inoculated with $0.5 \mathrm{McF}$ arland of Lactobacillus casei then incubated at $25,30,37,40$, and $45^{\circ} \mathrm{C}$. $\mathrm{pH}$ and bile salt resistance were done as recommended by (Hassan et al., 2012); MRS broth was prepared at $\mathrm{pH} 2.0,2.5,3.0$ and inoculated with 0.5 McFarland of Lactobacillus casei then incubated at $37^{\circ} \mathrm{C}$ for $24 \mathrm{~h}$. For bile salt resistance, MRS broth was prepared with a 
saturated bile solution that was prepared separately by dissolving powdered bile extract (Oxoid bile salts, Thermo Fisher Scientific Inc, UK, code: LP0055). The bile solution was then filtered and sterilized by $0.2 \mu$ filter and was added to two of the cultures to achieve a final concentration of $(0.2,0.5,1.0,2.0 \% \mathrm{~W} / \mathrm{V})$ and the second culture with $0 \%$ bile served as a control sample. The cultures were incubated at $37{ }^{\circ} \mathrm{C}$ for $3 \mathrm{~h}$. A plate count was done to assess the survival of $L$. casei using 10 -fold serial dilutions prepared in $0.1 \%$ peptone water. Bacterial growth was monitored by measuring absorbance with a spectrophotometer (Unicam, Uk) at $600 \mathrm{~nm}$. Antimicrobial activity; L. casei cell-free neutral supernatant was tested against a number of pathogens using agar well diffusion method (Hassan et al., 2012), to determine the antibacterial property of bacteriocin or bacteriocin-like substances (BLS) producing $L$. casei (Ehrmann et al., 2002).

\section{Animals}

\section{Animal care and husbandry}

Sixty adult Sprague-Dawley male albino rats weighing 130-150g were obtained from the animal house of National Organization for Drug Control and Research (NODCAR), Giza, Egypt and were housed in 12:12 h light/dark cycle, at an ambient temperature of $26 \pm 1{ }^{\circ} \mathrm{C}$. The rats had free access to food and water ad libitum. For adaptation, the rats were handled manually for one week before the experiment. All ethical issues regarding animal biosafety, reducing animal's suffering and distress were following the guidelines of NODCAR and were consistent with that of the National Institute of Health (NIH) Guide for Care and Use of Laboratory Animals (NIH, 2011).

\section{Experimental design and animal grouping}

The rats were randomly divided into six groups, 10 rats each; control animals and experimental animals which received Diethylnitrosamine (DENA) at a dose of $55 \mathrm{mg} / \mathrm{kg}$ body weight twice a week for 6 consecutive weeks (Li et al., 2017). After that, the experimental animals were further subdivided into groups (Table 1).
Blood sampling and biochemical and bacteriological analyses

At the end of the experimental period, blood samples were collected via retro-orbital venous plexus puncturing. Afterwards, serum was obtained by centrifugation at $3000 \mathrm{~g}$ for $15 \mathrm{~min}$ at $4^{\circ} \mathrm{C}$ using a cooling centrifuge (HERMLE Labortechnik $\mathrm{GmbH}$, Germany), and then it was frozen at $-80^{\circ} \mathrm{C}$ for biochemical analysis of alpha-fetoprotein (AFP), tumor necrosis factor (TNF-alpha), free Testosterone and antimullerian hormone (AMH) using the corresponding colourimetric ELISA kit for each (Abia Ref. DK.045.01.3, Fortress diagnostics Ref. BXE0811A, Sino Gene Clon Ref. SG20127, Diametra Ref DK0015 and Gene II ref A79765 respectively). Also, the serum levels of nitric oxide (NO) and glutathione peroxidase (GSHPX) were measured. Kits of NO and GSHPX were purchased from Biodiagnostic Company, Egypt. For bacteriological analysis, blood samples (5 $\mathrm{ml}$ ) were immediately placed in ethylene diamine tetraacetic acid-containing sterile tubes. Tissue samples of the testes were placed in $5 \mathrm{~mL}$ of sterile transport medium and were placed in an ultrasonic bath (Ultrasons, USA) for 5 minutes. A total aerobic plate count was made by placing $1 \mathrm{~mL}$ of the sample on brain-heart infusion agar (LabM, UK) and incubated at $37{ }^{\circ} \mathrm{C}$ for 3 days. After 3 days, the number of colonies formed on each plate was counted and corrected for the weight of the original tissue.

\section{Sperm cell concentrations}

Male rats were weighed and euthanized by cervical dislocation for dissection of reproductive organs, epididymis and testes. The caudal epididymis was immediately used for sperm count. Sperm cell concentrations were performed according to the technique adopted by (Bearden and Fuquay, 1980).

\section{Histological procedures}

Rats' testes were rapidly dissected, examined for gross appearance, weighed and immediately fixed in $10 \%$ neutral formalin for processing of paraffin sections. Approximately, fivemicrometer sections were cut and subjected to hematoxylin \& eosin staining (Bancroft and Lyton, 2018) and immunohistochemical techniques (Kiernan, 2015) using anti-androgen 
receptor and anti-caspase- 3 antibodies (Catalog NO: PA1-110 and PA1-29157 respectively). The primary antibodies used were rabbit polyclonal antibodies (Thermo Fisher Scientific Corporation, Fremont, CA, USA). They were supplied at a dilution of 1:100 and incubated with the slides for one hour at room temperature, followed by a reaction with biotinylated secondary antibody. After streptavidin peroxidase conjugation, 3,3diaminobenzidine (DAB) was used as a chromogen and hematoxylin was used as a counterstain. The antibody reactions of both appeared as brownish cytoplasmic discoloration. Despite always being a nuclear reaction, $A R$ immunoexpression could be shifted to stain cytoplasm if the androgen level is below the threshold to induce nuclear reaction as mentioned by (Al-Shathly et al., (2020). The positive controls for AR and caspase- 3 were the human prostate and tonsils respectively.

\section{Morphometric analysis}

Histomorphometric analysis of the STs was performed using ImageJ software (Java; NIH, Bethesda, Maryland, USA) (Rasband, 2007). Initial image visualization was done by light microscope (Olympus BX50F4, Shinjuku-ku, Tokyo, Japan) and then captured by a camera (AmScope digital camera MU500, Irvine, CA, USA)-based computer system. It was used for assessment of the tubular and luminal perimeters, the height of the tubular epithelium, Leydig cell area \& number and cross-sectional areas of the cross-cut sections of the STs. For this purpose, 10 different, nonoverlapping randomly captured photomicrographs at $\times 100$ magnification were used. Leydig cells were counted per unit area $\left(\mu \mathrm{m}^{2}\right)$ in five sections per sample according to (Zhang et al., 2013). Also, the area percent of AR and optical density of caspase-3 immunoreactivities were measured. It was evaluated in 10 different randomly captured photomicrographs at x100 magnification, for each group of animals.

\section{Statistical analysis}

Statistical analyses were done using SPSS software, version 23 (IBM SPSS Statistics for Windows, Armonk, NY, USA). Statistical significance was defined as a $P$ value less than 0.05 using one-way analysis of variance (ANOVA) and the comparison between groups was evaluated using post hoc (LSD) ANOVA test. The data were expressed as mean \pm SD .

\section{RESULTS}

Evaluation of the probiotic characteristics of $L$. casei

The behavior of $L$. casei at different $\mathrm{pH}$ varied, however, at $\mathrm{pH} 2.5$ and 3.0, the absorbance at $\mathrm{pH} 3$ was significantly increased $(\mathrm{p}<0.05)$ compared with $\mathrm{pH} \mathrm{2,} \mathrm{and} \mathrm{the} \mathrm{survival} \mathrm{of}$ bacteria was observed at all $\mathrm{pH}$ that indicated the ability of the isolate to tolerate the acidic $\mathrm{pH}$ (Table 2). Also, the strain was grown at different temperatures but the optimum temperature for the growth was $37^{\circ} \mathrm{C}$ (Table 2). The tolerance to bile concentration was significantly achieved $(p<0.05)$ until $1 \%$ then began to decrease at $2 \%$. (Table 2). Antibiotic susceptibility of $L$. casei against different antibiotics was evaluated and showed more resistance patterns to cefepime, ceftazidime, ciprofloxacin, doxycycline, oxytetracycline gentamicin, ampicillin/ sulbactam, and trimethoprim/ sulfamethoxazole in comparison to amikacin, colistin sulphate, piperacillin/tazobactam, and imipenem that displayed a sensitivity pattern (Table 3). Culture filtrate of Lactobacillus casei was evaluated against 7 pathogens, culture does not affect all serovars of Salmonella and $E$. coli species, while showed promising antimicrobial activity against $P$. aeruginosa, Enterococcus fecalis, and A. baumannii (Table 4). To assess bacterial translocation and whether $L$. casei cells were delivered to the blood and testes, we compared L. casei in the control group and the treated one. The incidence (rate) of translocation of $L$. casei was determined and showed no statistical significance between the control group and $D E N A+L A B$ group. This means that all animals in each group showed positive translocation of bacteria. However, there was a significant decrease in the number of colonies translocated to the blood and testes (Figure 1). This indicated that the isolate survived the different stresses encountered during the 6-week-DENA exposure and reached target tissues in an optimal number even though they were comparable to the control. 


\section{Mortality, clinical observations, gross testicular appearance and testicular weight}

No mortality was evident among the animals of the studied groups. No unusual clinical signs were detected on gross inspection of the animals. The resected testes in different groups appeared regular, smooth-surfaced with no gross nodules or focal masses. A significant testicular weight loss $(p<0.05)$ was observed in DENA-alone-treated animals when compared to control animals. $L A B$ and MDP treatment resulted in a significant increase $(p<0.05)$ in testicular weight, in relation to the DENAalone-treated animals with almost restoration of the control testicular weight. However, DOXalone treatment led to a more weight reduction with a statistical difference $(p<0.05)$, in relation to DENA-alone-treated group. Coadministration of MDP with DOX significantly increased $(p<0.05)$ testicular weight, in comparison to DOX-alone treatment (Figure 2).

Determination of the serum biomarkers of inflammation and oxidant/antioxidant balance

The data (Figure $3 \mathrm{~A}$ ) showed a significant increase $(p<0.05)$ in the serum level of TNF- $\alpha$ (a marker of inflammation) in DENA-alone-treated animals when compared to control rats and significantly decreased $(p<0.05)$ in all treated groups, in relation to the DENA group. Individual administration of either MDP or DOX had a better anti-inflammatory effect than LABtreated group however, both combined had no further anti-inflammatory effect. The antioxidant biomarker, glutathione peroxidase (GSHPX) in Figure 3B showed a significant decrease $(p<0.05)$ in DENA alone-treated group when compared to control rats and significantly increased $(p<0.05)$ in all treated groups. LAB treatment had the best antioxidant property, with almost normalization of the values when compared to the control. In regards to the oxidative status, there was a significant increase $(p<0.05)$ in the nitric oxide (NO) level in the DENA-alone-treated group when compared to the control group (Figure $3 \mathrm{C}$ ). The MDP-treated group showed a more significant decrease $(p<$ 0.05 ) in NO rather than LAB-treated group. DOX-treatment showed the worst effect with no significant difference compared to DENA alone-treated group.
Assessment of the endocrine and exocrine functions of the testis

Affording to the finding offered by Figures $4 A$ \& $B$, both serum testosterone and $A M H$ levels showed a significant decrease $(p<0.05)$ in DENAalone treated group when compared to control rats. All treatment options showed a significant increase $(p<0.05)$ in both hormones when compared to DENA-alone treatment. DOXalone treatment showed the worst effect on reversing testosterone levels. Evaluating the exocrine function of the testis (Figure $4 \mathrm{C}$ ), the data showed a significant decrease $(p<0.05)$ in sperm cell concentration in the DENA-alonetreated group, in comparison to the control animals. The applied treatment options showed a variable significant improvement $(p<0.05)$ when compared to the DENA-alone-treated group. More surprising, both LAB- and DOXalone treatment showed a significant increase $(p<0.05)$ in sperm cell count when compared to the control value.

\section{Evaluation of the tumor markers}

There was a significant increase $(p<0.05)$ in serum level of AFP in DENA-alone-treated animals when compared to the control animals. Almost all treatment options showed a significant decrease $(p<0.05)$ in AFP when compared to the DENA-alone-treated group. DOX treatment had the best effect on reversing AFP level however, MDP treatment had no significant effect (Figure 5).

\section{Histological findings Hematoxylin and eosin (H \& E) observations}

Examination of $\mathrm{H}$ \& $\mathrm{E}$ stained sections of the control testes showed normal tubular histoarchitecture with compactly arranged seminiferous tubules (STs) separated by intertubular connective tissue stroma containing Leydig cells and blood capillaries (BVs) (Figure 6). However, the testes of all animals of the DENA-alone-treated rats revealed marked tubular atrophy with contracted lumina while, others showed dilated ones. The intertubular spaces are widened with congested thick-walled BVs. The tubular epithelium showed maturation depletion leaving Sertoli cells-only tubules due to marked degeneration of the developing spermatogenic 
cells (Figure 7a,b). Disorganized exfoliated germ cells with loss of normal cellular association was noted. Apoptotic spermatogenic cells appeared with deeply acidophilic cytoplasm and clear halos all-around due to cell shrinkage (Figure 7c). Interestingly, all sections showed Leydig cell hyperplasia that appeared in 2 forms; multifocal and diffuse patterns that were noncompressive to STs. Many Leydig cells showed vacuolated cytoplasm (Figure 7b,d).

Individual administration of either MDP (Figure 8) or LAB (Figure 9) showed a remarkable improvement of STs. They appeared closely related with almost normal tubular epithelium in most STs. The germinal epithelium was restored in the LAB-treated group with almost recovery of spermatogenesis. In the MDPtreated group, the interstitial spaces were slightly widened by thick-walled congested blood vessels and less frequent focal lesions of Leydig cell hyperplasia however, seemingly normal Leydig cells and BVs were evident in all LAB-treated rats.

In all sections, DOX treatment either alone (Figure 10a,b) or combined with MDP (Figure 11) groups showed atrophic STs with degenerated, depleted, and exfoliated tubular epithelium. Apoptotic spermatogonia, apoptotic spermatocytes, and intraepithelial vacuolizations were seen within the germinal epithelium which denoted germ cell loss. Leydig cells appeared normal with congested thickwalled BVs (Figure 10a,b). Sertoli cells-only tubules and multiple basal intraepithelial macrovacuoles were seen in DOX/MDP combination group due to depletion of the developing germ cells. Leydig cells were almost normal (Figure 11).

\section{PAS stain observations}

Histological analysis of PAS-stained testicular sections of the control animals revealed intense magenta red (PAS-positive) basal lamina of the tubular basement membrane (BM) and acrosomic vesicles of early (rounded, occupy adluminal position) and late (elongated, occupy a luminal position) spermatids. PAS stained sections are better to demonstrate subtle features of spermatid acrosomes and hence the different stages of the spermatogenic cycle (Figure 12a). However, the DENA-alone-treated group showed a thickened PAS-positive BM. PAS-positive elongated and round spermatids were seen in abnormal positions (Figure 12b).

Administration of MDP (Figure 12c) and LAB (Figure 12d) treatments showed variable degrees of recovered germinal epithelium overlying normal BM. PAS-positive elongated spermatids were seen attached at luminal position. Round spermatids were seen at adluminal position, underlying elongated spermatids. On the other hand, DOX treatment showed degenerated spermatogenic epithelium and almost thickened BM. Exfoliated PAS-positive germ cells were seen filling the luminal space (Figure 12e). Co-administration of MDP with DOX showed slightly thickened PAS-positive BM with PAS-positive elongated spermatids (Figure 12f).

\section{Immunohistochemical findings}

Testicular sections stained with anti-caspase- 3 antibody revealed diffuse negative immunoreaction in the control group (Figure 13a). However, a diffuse strong positive cytoplasmic reaction was noted in the different cells of the germinal epithelium in DENA alone, DENA+DOX, and DENA+DOX+MDP-treated groups (Figure 13b, e, $f$ respectively). Meanwhile, the immunoreaction was diffusely weak positive all over the section in DENA+MDP and DENA+LAB-treated groups (Figure 13c,d respectively). Interestingly, AR immunoexpression showed markedly positive cytoplasmic immunoreaction limited to the hyperplastic Leydig cell mass in testicular sections of DENA-alone-treated animals (Figure 14b). Meanwhile, a minimal reaction was recorded in the treated animal groups (Figure 14c-f).

\section{Histomorphometric results Tubular morphometric parameters}

There was a significant decrease $(p<0.05)$ in the mean tubular, mean lumenal perimeters, mean cross-sectional areas of STs, and the mean thickness (height) of the tubular epithelium in the DENA-alone-treated group when compared to the control group. Meanwhile, the administration of MDP and $L A B$ showed a significant increase $(p<0.05)$ in the measured parameters, in relation to DENA-treated group. 
However, administration of DOX showed a more significant decrease $(p<0.05)$ when compared to DENA-treated group. Coadministration of MDP with DOX showed a slight significant increase $(p<0.05)$ in the measured parameters when compared to DOXalone-treatment. Overall, DOX treatment had an additional worsening effect on the measured parameters which was slightly reversed by further addition of MDP (Figure 15A-D).

\section{Leydig cell number and area}

There was a significant increase $(p<0.05)$ in the mean Leydig cell area (LCA) and mean Leydig cell number (LCN) per unit area in the DENAalone-treated group, when compared to that of the control animals. However, all treatment options resulted in a significant reduction $(p<$ 0.05 ) in the 2 estimated parameters, when compared to the DENA-alone-treated group with almost complete restoration when compared to control animals. Exceptionally, DENA+MDP-treated animals showed about 50\% and $35 \%$-only-reduction in the LCA and LCN respectively. These findings referred to a beneficial effect of the current treatment options, in the reversal of Leydig cell mass with about 35-50\%-only-efficacy of MDP in treating hyperplastic Leydig cells (Figure 16A, B).

\section{Histomorphometric evaluation of the anti-AR and anti-caspase-3 immunostained sections}

The DENA-alone-treated group showed a significant increase $(p<0.05)$ in the mean optical density of caspase-3 immunoreaction, when compared to control. When comparing the treatment options to DENA-alone-treated group, administration of either MDP or LAB resulted in a significant decrease $(p<0.05)$ in the mean optical density however, DOX and DOX+MDP treatments had no significant comparable effects. Regarding the mean area percent of $A R$ immunoreaction, it showed a significant increase $(p<0.05)$ in relation to control, which was significantly $(p<0.05)$ reversed when attempting the treatment options in the studied groups (Figure 17A, B).

\section{DISCUSSION}

Diethynitrosamine (DENA) is a potent $\mathrm{N}$-nitroso compound that has been reported to have a heptocarcinogenic effect several years later
(Tolba et al., 2015). Therefore, the study evaluated the DENA-induced male reprotoxicity and the role of the testicular expression of $A R$ and caspase- 3 activities using biochemical, histological and immunohistochemical studies. Moreover, the study was the first to assess 2 treatment options, a newly synthesized pyridazine derivative, MDP and a probiotic, $L$. casei against the testicular histopathological changes induced by DENA and compared both agents versus a reference chemotherapeutic agent, doxorubicin.

First, the current study evaluated $L$. casei for their probiotic characteristics; hence they can arrive alive to targeted organs (Hassan et al., 2012). The antibiotic sensitivity pattern, $L$. casei isolate showed antibiotic resistance to cell wall inhibitors as well as nucleic acid inhibitors and this profile indicated its probiotic potential to use as a therapeutic regime. In agreement, (Ali et al., 2018) reported similar results.

In the current study, the $\mathrm{H} \& \mathrm{E}$ findings showed that administration of DENA induced Leydig cell hyperplasia (LCH) in the form of interstitial focal and diffuse lesions. This finding was confirmed by the significant increase in both Leydig cell area (LCA) and Leydig cell number (LCN) when compared to control animals. A previous study (Kaya et al., 2019) was inconsistent with the current observation. Such discrepancy might be attributed to the dose regimen and frequency of DENA administration.

Although, the Leydig cells (LCS) are the main producers of testosterone (De Miguel et al., 2018), the serum level in the same animal group showed a significant decrease when compared to the control group that might be explained by a direct injurious effect with lack of the endocrine function, as evident by LCS vacuolation in $H$ \& $E$ findings. Also, the overproduction of TNF- $\alpha$ in this animal group could affect testosterone secretion as described by (Bianchi, 2019) who mentioned that testosterone biosynthesis is regulated by various cytokines like TNF- $\alpha$ whose overexpression inhibits testicular biosynthesis of testosterone. Therefore, the decreased serum testosterone level might explain such hyperplastic changes in LCs induced by DENA as demonstrated by (Steinbach et al., 2015). 
Table 1. Animal grouping and study design.

\begin{tabular}{|c|c|}
\hline Group & Experimental procedures \\
\hline Group 1 (control group) & $\begin{array}{l}\text { Control animals received the vehicle corresponding to each treatment twice a week for } 4 \\
\text { consecutive weeks; normal saline }(2 \mathrm{ml} / \mathrm{kg} \text {, ip) and PBS }(1 \mathrm{ml} / \mathrm{kg} \text {, via oral gavage). }\end{array}$ \\
\hline Group 2 (DENA group) & $\begin{array}{l}\text { The DENA-treated animals received normal saline }(2 \mathrm{ml} / \mathrm{kg} \text {, ip) and PBS }(1 \mathrm{ml} / \mathrm{kg} \text {, via oral } \\
\text { gavage) twice a week for another } 4 \text { consecutive weeks. }\end{array}$ \\
\hline $\begin{array}{l}\text { Group } 3 \\
\text { (DENA + MDP) }\end{array}$ & $\begin{array}{l}\text { The DENA-treated animals received MDP (10 mg/kg, ip) twice a week for another } 4 \\
\text { consecutive weeks. }\end{array}$ \\
\hline $\begin{array}{l}\text { Group } 4 \\
\text { (DENA + LAB) }\end{array}$ & $\begin{array}{l}\text { The DENA-treated animals received Lactobacillus ( } 1.5 \times 10^{9} \mathrm{CFU} / \mathrm{kg} \text { ) (Matuskova et al., 2017), } \\
\text { via oral gavage twice a week for another } 4 \text { consecutive weeks. }\end{array}$ \\
\hline $\begin{array}{l}\text { Group } 5 \\
\text { (DENA + DOX) }\end{array}$ & $\begin{array}{l}\text { The DENA-treated animals received DOX (10 mg/kg, ip) (Tutun et al., 2019), twice a week for } \\
\text { another } 4 \text { consecutive weeks. }\end{array}$ \\
\hline $\begin{array}{l}\text { Group } 6 \\
\text { (DENA + MDP + DOX) }\end{array}$ & The DENA-treated animals received both MDP+DOX as aforementioned. \\
\hline
\end{tabular}

Table 2. Assessment of pH, temperature and bile tolerance of Lactobacillus casei after allocated incubation period for each.

\begin{tabular}{|c|c|c|c|c|c|c|c|c|c|c|c|c|c|}
\hline \multirow{2}{*}{ 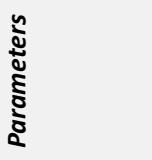 } & \multirow{2}{*}{$\begin{array}{l}\overline{0} \\
\overline{0} \\
0 \\
0\end{array}$} & \multicolumn{3}{|c|}{ pH tolerance } & \multicolumn{5}{|c|}{ Temperature resistance $\left({ }^{\circ} \mathrm{C}\right)$} & \multicolumn{4}{|c|}{ Bile salt tolerance (\%) } \\
\hline & & 2.0 & 2.5 & 3.0 & 25 & 30 & 37 & 40 & 45 & 0.2 & 0.5 & 1 & 2 \\
\hline $\begin{array}{c}\text { Absorbance } \\
\Delta A_{560}\end{array}$ & $\begin{array}{c}1.58 \pm \\
0.01\end{array}$ & $\begin{array}{l}0.003 \pm \\
0.002^{*}\end{array}$ & $\begin{array}{c}0.07 \pm \\
0.05^{*}+\end{array}$ & $\begin{array}{l}0.96 \pm \\
0.0 *+\end{array}$ & $\begin{array}{l}0.56 \pm \\
0.04^{*}\end{array}$ & $\begin{array}{l}0.8 \pm \\
0.0^{*}\end{array}$ & $\begin{array}{c}1.3 \pm \\
0.0 * \$\end{array}$ & $\begin{array}{l}1.17 \pm \\
0.01^{*}\end{array}$ & $\begin{array}{c}0.5 \pm \\
0.05^{*}\end{array}$ & $\begin{array}{c}0.8 \pm \\
0.05 * \#\end{array}$ & $\begin{array}{c}0.35 \pm \\
0.05^{*} \#\end{array}$ & $\begin{array}{c}0.1 \pm \\
0.02^{*} \#\end{array}$ & $\begin{array}{l}0.09 \pm \\
0.05^{*}\end{array}$ \\
\hline $\begin{array}{l}\text { Plate count } \\
\text { (survival) } \\
\text { No. of } \\
\text { colony } \\
\text { (CFU/ml) }\end{array}$ & $\begin{array}{c}S \\
>300\end{array}$ & $\begin{array}{c}S \\
>50\end{array}$ & $\begin{array}{c}S \\
70\end{array}$ & $\begin{array}{c}S \\
>200\end{array}$ & $\begin{array}{c}\mathrm{S} \\
>30\end{array}$ & $\begin{array}{c}S \\
>230\end{array}$ & $\begin{array}{c}S \\
>270\end{array}$ & $\begin{array}{c}S \\
>120\end{array}$ & $\begin{array}{c}S \\
>96\end{array}$ & $\begin{array}{c}S \\
>30\end{array}$ & $\begin{array}{c}S \\
>88\end{array}$ & $\begin{array}{c}S \\
>220\end{array}$ & $\begin{array}{l}\text { NS } \\
0.0\end{array}$ \\
\hline
\end{tabular}

* significantly different when compared to control using two-way ANOVA, $P<0.05$

† significantly different when compared to $\mathrm{pH} 2$ using two-way ANOVA, $P<0.05$

$\$$ significantly different when compared to temperature $25,30,40,45^{\circ} \mathrm{C}$ using two-way ANOVA, $P<0.05$

\# significantly different when compared to bile concentration $2 \%$ using two-way ANOVA, $P<0.05$

S: Survival of bacteria at different parameters

NS: not survive

Table 3. Susceptibility pattern of the different antibiotics used for L. casei R: resistant, S: sensitive

\begin{tabular}{|c|c|c|c|c|c|c|c|c|}
\hline \multirow{2}{*}{$\begin{array}{l}\text { No. } \\
1\end{array}$} & \multicolumn{2}{|c|}{ Antibiotic class } & \multicolumn{2}{|c|}{ Antibiotic name } & \multirow{2}{*}{$\begin{array}{l}\text { Abb } \\
S A M\end{array}$} & \multirow{2}{*}{$\begin{array}{l}\boldsymbol{\mu g} / \text { desk } \\
10 / 10\end{array}$} & \multicolumn{2}{|c|}{$\begin{array}{l}\text { Antimicrobial activity } \\
(\mathrm{mm}) \text { pattern }\end{array}$} \\
\hline & \multirow[t]{4}{*}{$\beta$-lactamase } & \multirow[t]{2}{*}{ Penicillins } & \multicolumn{2}{|c|}{ Ampicillin/sulbactam } & & & $0.0 \pm 0$ & $\mathrm{R}$ \\
\hline 2 & & & \multicolumn{2}{|c|}{ Piperacillin/tazobactam } & TZP & $100 / 10$ & $25 \pm 1.15$ & $S$ \\
\hline 3 & & \multirow[t]{2}{*}{ Cephalosporins } & $3^{\text {rdgeneration }}$ & Ceftazidime & CAZ & 30 & $0.0 \pm 0$ & $\mathrm{R}$ \\
\hline 4 & & & $4^{\text {th }}$ generation & Cefepime & FEP & 30 & $0.0 \pm 0$ & $\mathrm{R}$ \\
\hline \multirow[t]{2}{*}{5} & \multirow{2}{*}{\multicolumn{2}{|c|}{ Aminoglycoside }} & \multicolumn{2}{|l|}{ Amikacin } & AK & 30 & $16 \pm 0.5$ & $\mathrm{~S}$ \\
\hline & & & \multicolumn{2}{|l|}{ Gentamycin } & GN & 10 & $10 \pm 0.5$ & $\mathrm{R}$ \\
\hline 6 & \multicolumn{2}{|c|}{ Fluoroquinolone } & \multicolumn{2}{|l|}{ Ciprofloxacin } & CIP & 5 & $10 \pm 0.5$ & $\mathrm{R}$ \\
\hline 7 & \multicolumn{2}{|l|}{ Lipopiptide } & \multicolumn{2}{|c|}{ Colistin sulphate } & CT & 10 & $30 \pm 0.28$ & $\mathrm{~S}$ \\
\hline 8 & \multicolumn{2}{|l|}{ Carbapenem } & \multicolumn{2}{|c|}{ Imipenem } & IMP & 10 & $18 \pm 0$ & $\mathrm{~S}$ \\
\hline \multirow[t]{2}{*}{9} & \multirow{2}{*}{\multicolumn{2}{|c|}{ Tetracycline }} & \multicolumn{2}{|l|}{ Oxytetracycline } & OXY & 10 & $10 \pm 0$ & $\mathrm{R}$ \\
\hline & & & \multicolumn{2}{|l|}{ Doxycycline } & DOX & 30 & $8.0 \pm 0$ & $\mathrm{R}$ \\
\hline 10 & \multicolumn{2}{|c|}{$\begin{array}{l}\text { Dihydrofolate reductase inhibitor / } \\
\text { Sulfonamide }\end{array}$} & \multicolumn{2}{|c|}{$\begin{array}{l}\text { Trimethoprim/ } \\
\text { Sulfamethoxazole }\end{array}$} & SXT & $\begin{array}{l}1.25 / \\
23.75\end{array}$ & $0.0 \pm 0$ & $\mathrm{R}$ \\
\hline
\end{tabular}


Table 4. Antimicrobial activity of $L$. casei against different tested pathogens

\begin{tabular}{|l|c|}
\hline \multicolumn{1}{|c|}{ Tested Pathogen } & Antimicrobial activity (mm) \\
\hline Salmonella enetrica serovar Typhimurium & $0.0 \pm 0$ \\
\hline Salmonella enetrica serovar Paratyphi A & $0.0 \pm 0$ \\
\hline Salmonella enetrica serovar Typhi & $0.0 \pm 0$ \\
\hline E. coli & $0.0 \pm 0$ \\
\hline Pseudomonas aeruginosa & $22.5 \pm 0.5$ \\
\hline Enterococcus fecalis & $20.5 \pm 0$ \\
\hline Acinetobacter baumannii & $25.0 \pm 0.2$ \\
\hline
\end{tabular}
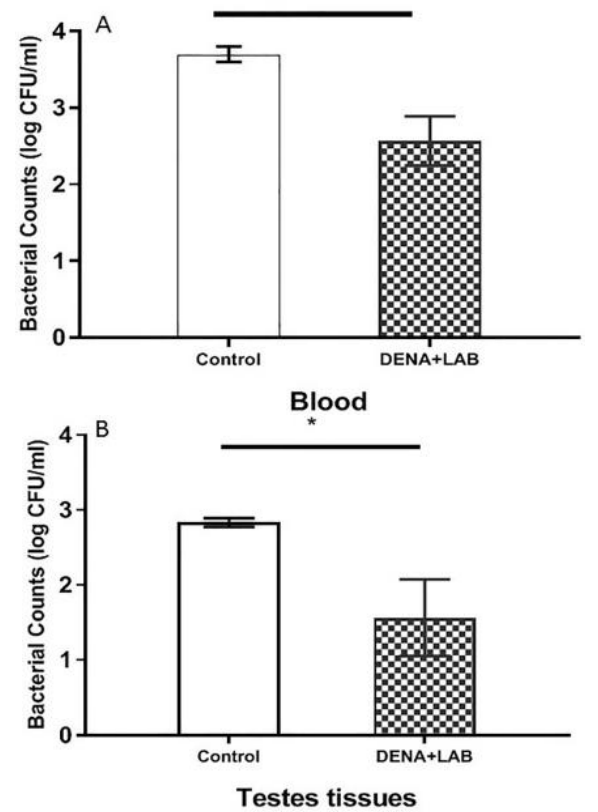

Figure 1. Translocation of $L$. casei to the blood and testes after twice-weekly treatment for 4 weeks in control animals and after 6-week-DENA-exposed group. * DENAtreated group significantly compared with control testes; P-value < 0.05; ** DENA-treated group significantly compared with control blood; P-value $<0.05$.

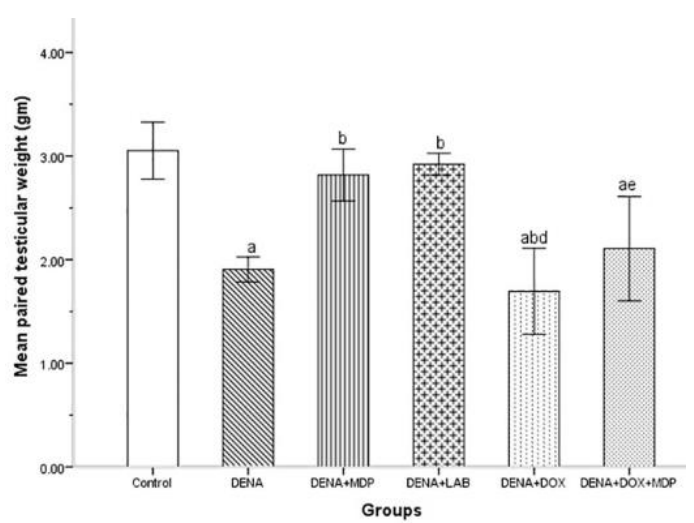

Figure 2. Changes in the weight of the paired testes of the animals in the studied groups (mean $\pm S D, n=10$ ). a: significant versus control group, $b$ : significant versus DENA group, d: significant versus MDP and $L A B$, e: significant versus DOX, using post hoc ANOVA, P-value $<0.05$.
They referred to a major role of $\mathrm{LH}$ level disruption in Leydig Cell tumors (LCTs) induction by chemicals. According to the negative feedback regulation, the LH level may increase to counter the decreased serum testosterone with subsequent proliferative effects on LCs.

On the contrary, LCTs are non-germ cell tumors where the AFP level is negative or shows nonsignificant abnormalities as declared in case reports presented by (Zhu et al., 2018). So, an extended research workup is warranted to validate the increase of serum levels of AFP in such cases of animal LCH. Although LCTs represent the most frequent tumors of gonadal stroma in humans (Pozza et al., 2019), little is known in the literature whether human exposure to DENA contributes to testicular tumorigenesis. Conversely, (Akingbemi et al., 2004) reported an increase in Leydig cell populations in di-(2-ethylhexyl) phthalatetreated rats with elevated serum testosterone levels. They reported a direct stimulatory effect on LH secretion with compensatory proliferative effects on LCs stimulating testosterone secretion.

In our study, a negative feedback mechanism was expected that unveil such discrepancy. Analysis of serum AMH revealed a significant decrease when compared to control rats. The concomitant decrease of both testosterone and $\mathrm{AMH}$ could indicate a lack of functional testicular tissue as clarified by (Xu et al., 2019) who reported a co-decrease of both hormones in anorchia and severe Klinefelter syndrome. In correlation with the immunohistochemical observations of $A R$, the DENA-treated rats showed a significant increase in the area \% of AR immunostaining when compared to control animals, which could be a response of the expected increase in serum LH levels as suggested by Zirkin and Papadopoulos, 2018 

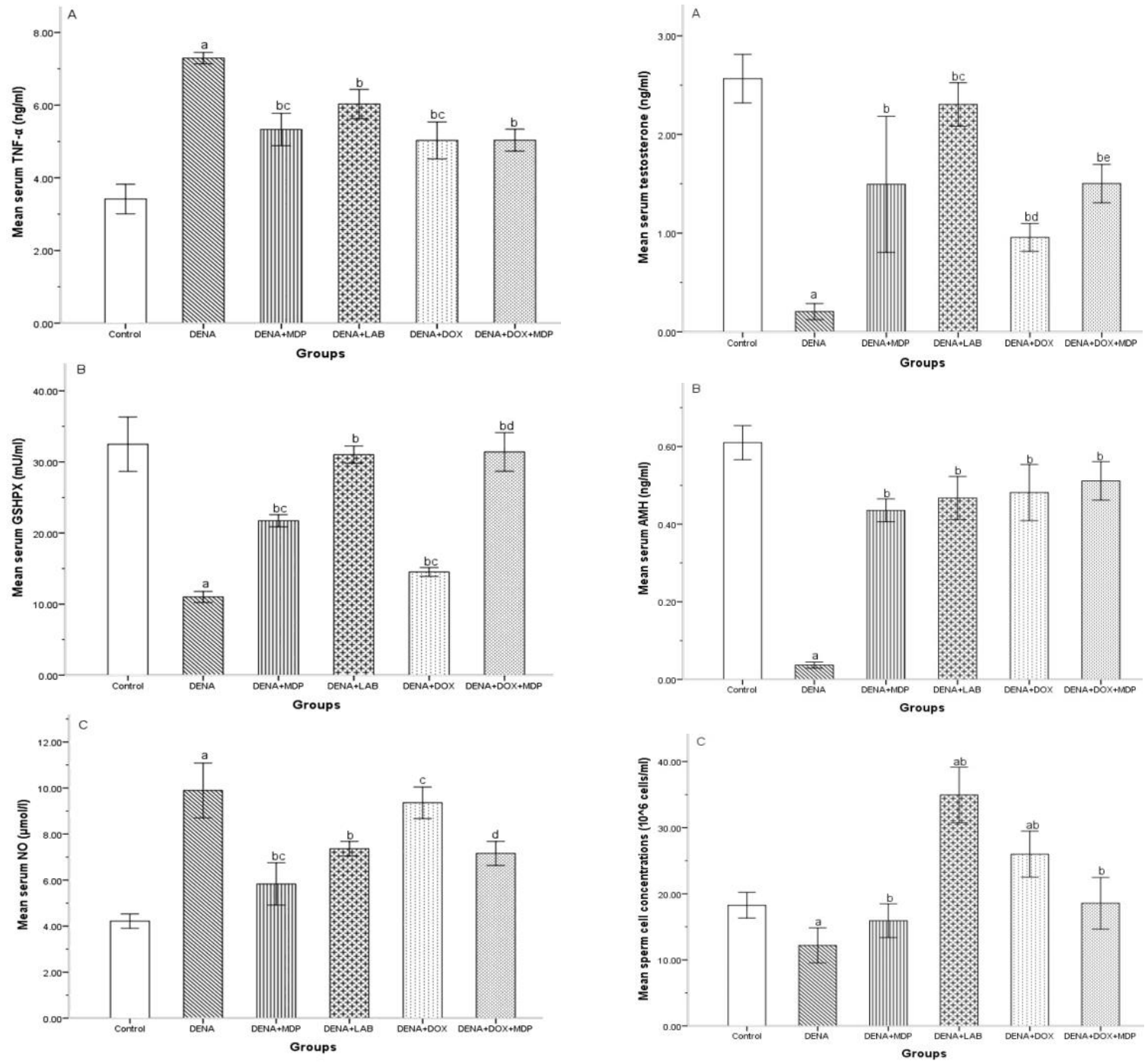

Figure 3. Changes in the serum levels of TNF- $\alpha$, NO and GSHPX in different groups (mean $\pm S D, n=10$ ). a: significant versus control group, $b$ : significant versus DENA group, $c$ : significant versus $L A B, d$ : significant versus DOX using post hoc ANOVA, P-value $<0.05$.

who declared that prolonged LH stimulation of LCs could affect the expression levels of proteins and enzymes involved in steroidogenesis. In addition, DENA treatment exerted toxic effects on the STs in the same group. The H \& E supported by PAS stain findings revealed tubular atrophy, thickened BM and reduced epithelial thickness which affected sperm cell concentrations. These findings were corroborated by the histomorphometric measurements of the tubular, luminal perimeters, epithelial height and cross-sectional profiles which showed a significant decrease in all parameters in comparison to the control group.

Figure 4. Changes in serum levels of testosterone, AMH and sperm cell concentrations in the different groups (mean $\pm S D, n=10$ ). a: significantly versus control group, $b$ : significant versus DENA group, $\mathrm{c}$ : significant versus MDP group, d: significant versus MDP and LAB-treated groups, e: significant versus DOX-treated group using post hoc

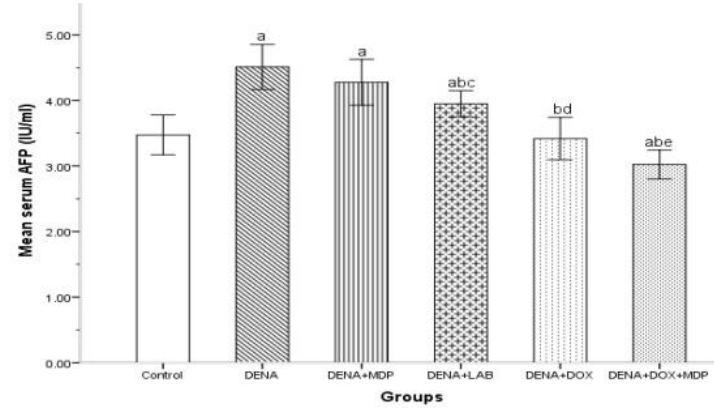

ANOVA, P-value $<0.05$.

Figure 5. Changes in serum level of Alpha-fetoprotein (AFP) in the studied groups (mean $\pm S D, n=10$ ). a: significantly versus control group, b: significantly versus DENA-alone group, c: significantly versus MDP-treated group, d: significantly versus MDP and LAB groups, e: significantly versus DOX group using post hoc ANOVA, Pvalue $<0.05$. 


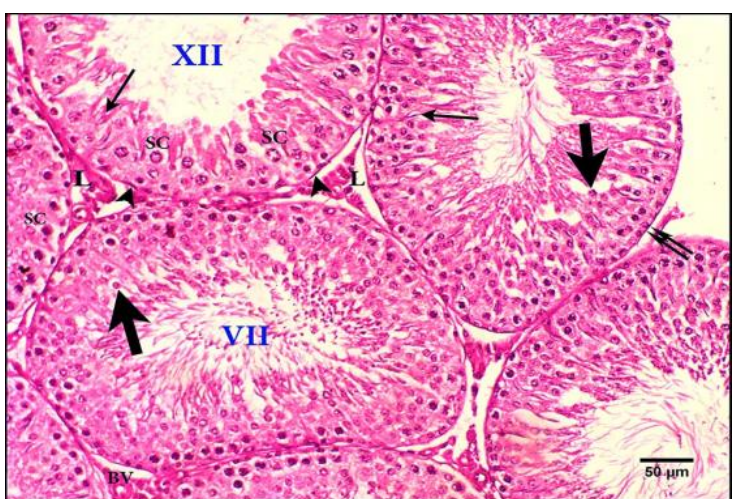

Figure 6. $\mathrm{H}$ and $\mathrm{E}$ stained photomicrograph of the control group showing closely related seminiferous tubules with different stages (stage VII and XII) of spermatogenic cycle. Spermatogonia (double arrows), primary spermatocytes (SC), round spermatids (thick arrows) and the elongating spermatids (thin arrows) are seen. Myoid cells (arrowheads) are clear. Leydig cells (L) and blood capillaries (BV) appear normal. Scale bar $50 \mu \mathrm{m}$.

These observations were in agreement with that of (Kaya et al., 2019). Furthermore, apoptotic changes were observed in the spermatogenic cells which were confirmed by the immunohistochemical staining of caspase- 3 activity that revealed a significant increase in the optical density when compared to the control group. Hence, there was a moderate decrease in testicular weight due to compensation by the hyperplastic LCs. Taken in mind the biochemical correlation, DENA treatment in rats achieved a significant increase in both serum levels of TNF and NO with a marked reduction in glutathione peroxidase (GSH) suggesting different aspects entangled in DENA induced-reproductive toxicity. Inflammatory and oxidative mechanisms were proposed. Disrupted antioxidant defense system and enhancement of apoptotic signaling pathways as confirmed by the $\mathrm{H}$ \& $\mathrm{E}$ findings and caspase-3 immunostaining were also involved. This was supported by (Sheweita et al., 2017) who reported similar biochemical mechanisms of nitrosamines-induced testicular intoxication in rabbits.

In both MDP and LAB-treated animals, the H \& E observations revealed an improvement of the histoarchitecture of STs of both groups which were parallel with the PAS findings. Recovery of the germinal epithelium was observed and restoration of stages of the spermatogenic cycle was evident in PAS findings.
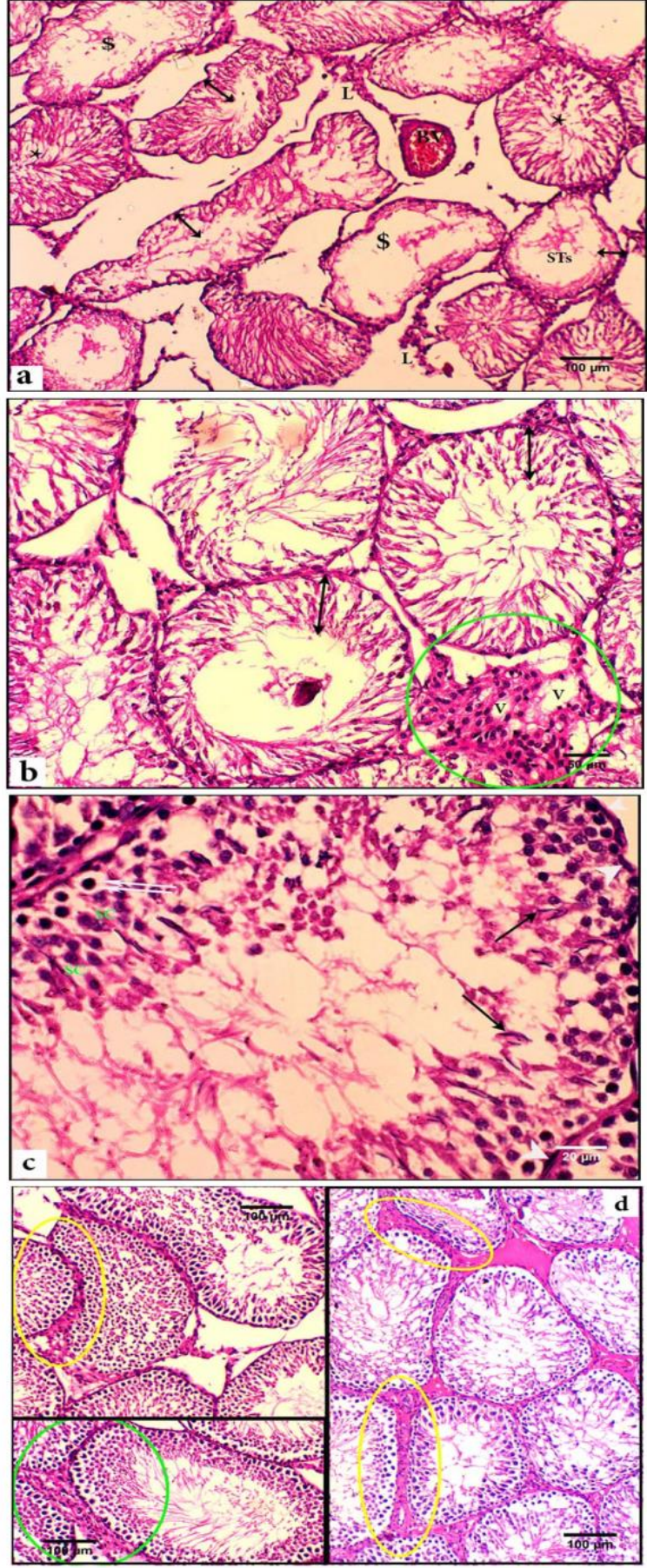

Figure 7. Histopathology of testis under the effect of DENA-alone treatment. $\mathrm{H}$ and $\mathrm{E}$ stained photomicrographs of the DENA alone-treated group showing marked tubular (STs) atrophy with contracted lumina (stars), other are dilated (dollar signs). The tubular epithelium (doubleheaded arrows) shows apoptotic spermatogonia (doublearrows) and primary spermatocytes (SC). Elongated spermatids (arrows) are detached from Sertoli cells. Myoid cells (arrowheads) appear with enlarged nuclei. Interstitial spaces show Leydig cells hyperplasia; focal (green circles) and diffuse (yellow circles) lesions. Leydig cells show multiple vacuolations (V). Congested thick-walled blood vessels (BV) are also seen. Scale bar $20 \mu \mathrm{m}$ (c), $50 \mu \mathrm{m}$ (b), $100 \mu \mathrm{m}(\mathrm{a}, \mathrm{d})$ 


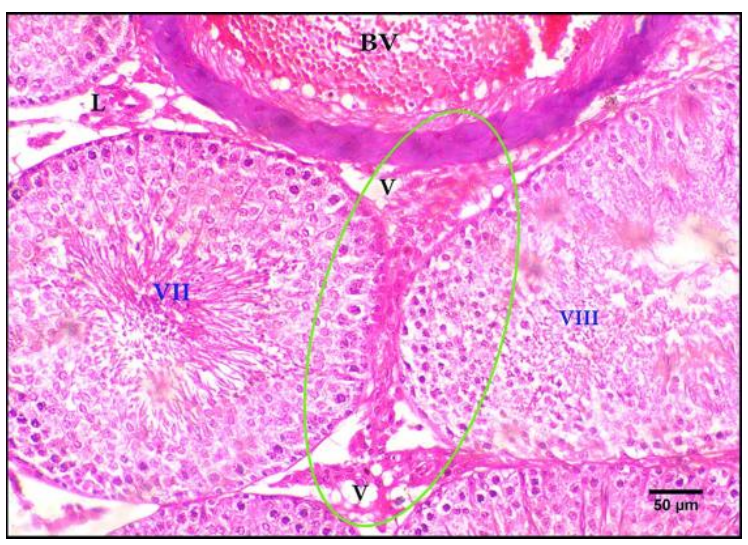

Figure 8. Histology of the testis showing restoration of the spermatogenic cycle under the effect of MDP treatment. $\mathrm{H}$ and $E$ stained photomicrograph of the DENA + MDPtreated group showing closely related normally populated STs at different stages (VII, VIII). Focal lesion of Leydig cell hyperplasia (green circle) with vacuolated cytoplasm (V) is observed. Blood capillaries (BV) appear congested and thick-walled. Scale bar $50 \mu \mathrm{m}$

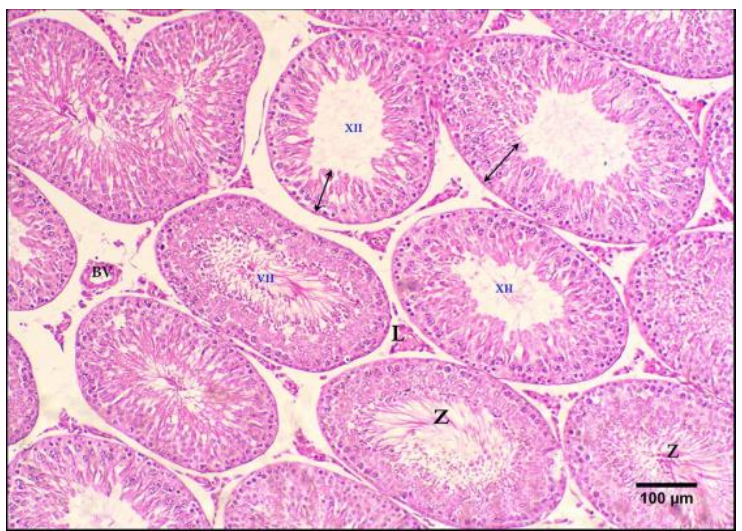

Figure 9. Histology of the testis under the effect of $L A B$ treatment. $\mathrm{H}$ and $\mathrm{E}$ stained photomicrograph of the DENA+ LAB-treated group showing well-organized STs with normally populated epithelium (double-headed arrows) with different stages (VII and XII). Active free spermatozoa (Z) is prominent. Normal Leydig cells (L) and normal blood capillaries (BV) are seen. Scale bar $100 \mu \mathrm{m}$

These signs of improvement were reflected in sperm cell concentrations with significant changes in both groups. In agreement, (Inatomi and Otomaru, 2018) reported a positive reproductive effect and an increase in sperm count after 6-week probiotic treatment, in broiler breeders. Regarding Leydig cell population, there was an almost complete restoration of the normal distribution of LCs in LAB-treated animals, however, MDP-treated rats have still shown minimal $\mathrm{LCH}$.
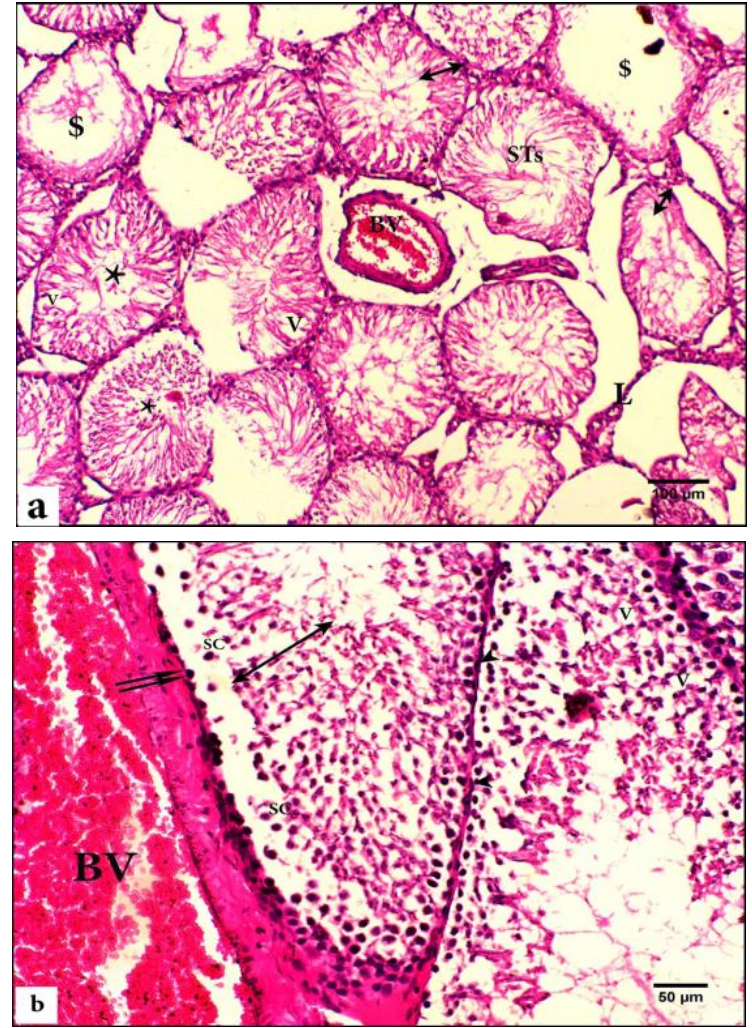

Figure 10. $\mathrm{H}$ and $\mathrm{E}$ stained photomicrographs of the DENA + DOX-treated group shows atrophic seminiferous tubules (STs). Most of them appear with dilated lumina (dollar signs), others appear contracted (stars). Spermatogenic cells (double-headed arrows) shows marked exfoliation and detachment from the underlying tubular BM. Apoptotic spermatogonia (double-arrows) and primary spermatocytes (SC) are seen. Vacuolations (V) are seen within the germinal epithelium. Leydig cells (L) appear normal with congested thick-walled BV. Scale bars $50 \mu \mathrm{m}$ (b), $100 \mu \mathrm{m}$ (a)

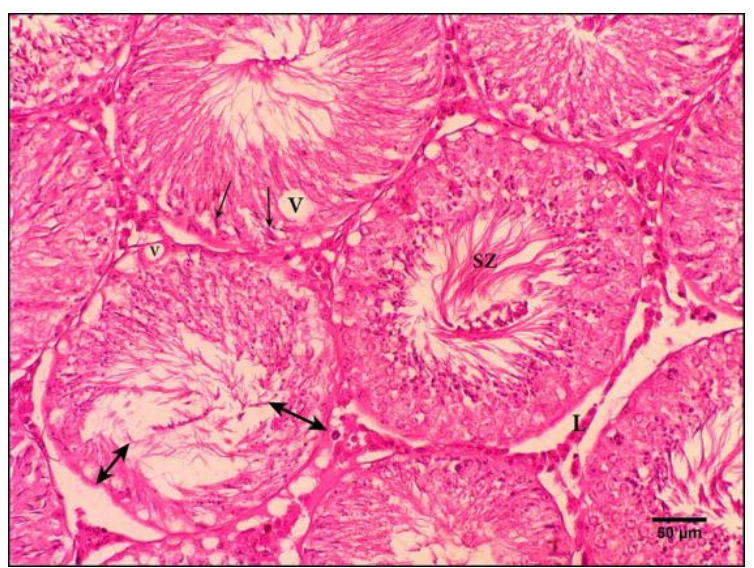

Figure 11. Histopathology of the testis under the effect of DOX/MDP treatment. $\mathrm{H}$ and $\mathrm{E}$ stained photomicrograph of the DENA+DOX + MDP-treated group shows packed atrophic STs. Most of them are Sertoli cells-only tubules (double-headed arrows), few are populated by spermatogenic cells. Few spermatozoa (SZ) are released. Basal macrovacuoles (V) are seen within the germinal epithelium. Almost normal Leydig cells (L) are seen. Scale bar $50 \mu \mathrm{m}$ 


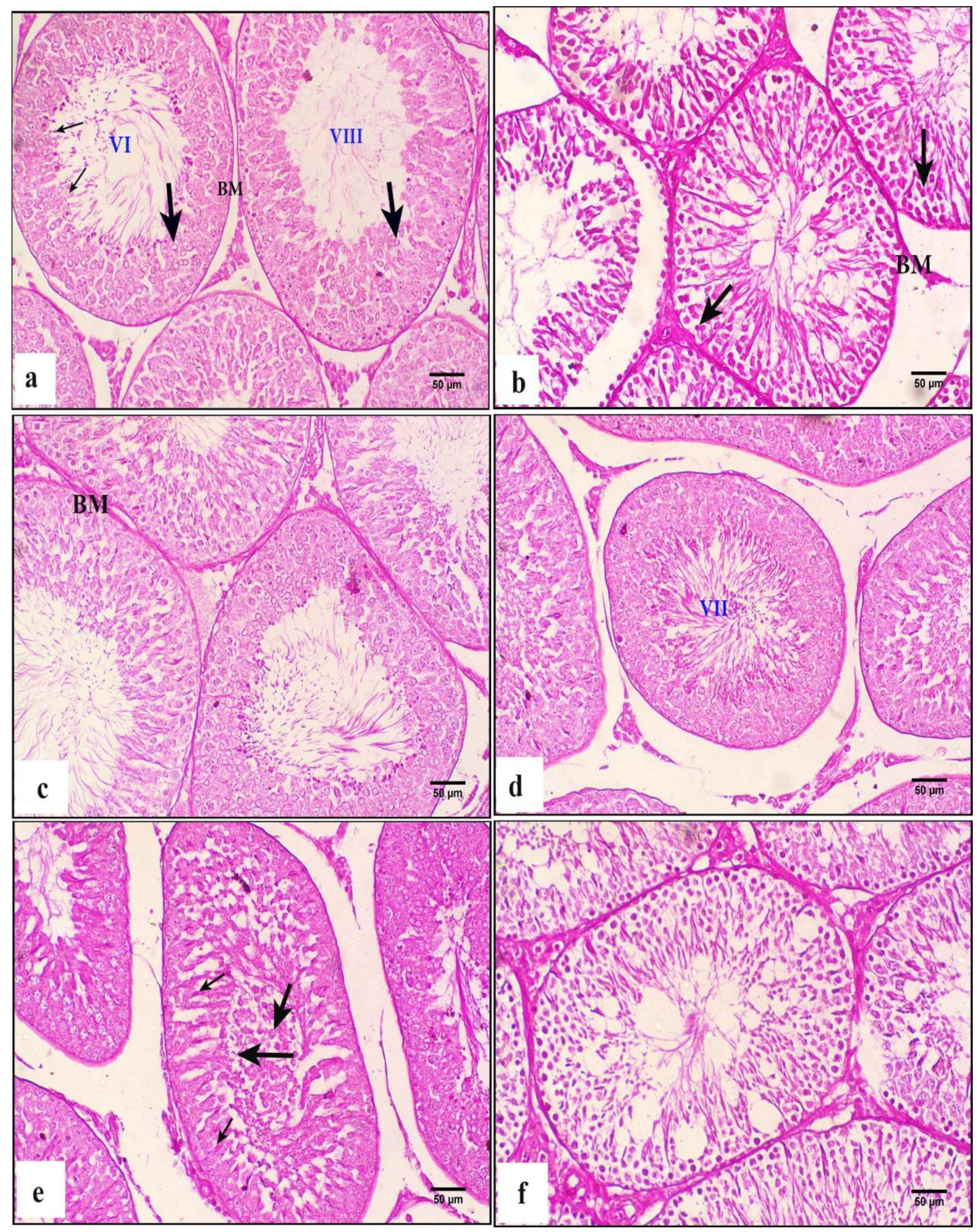

Figure 12. PAS-stained light micrographs of testicular sections of the studied groups. Control group (a) shows STs with a thin PAS-positive BM. Early staged STs (VII) shows 2 layers of spermatids; round (thick arrows) and elongated (thin arrow) and one layer in late-stage (VIII). DENA alone-treated group (b) shows a thickened PAS-positive BM. Also. Round spermatid (thick arrow), are seen disorganized near the BM. DENA+MDP group (c) shows recovered spermatogenic cells lying on regular thin PAS-positive BM. DENA+LAB group (d) shows early-stage (VII) STs with regular thin PAS-positive BM. DENA + DOX group (e) show thick PAS-positive BM. Exfoliated germ cells and round spermatids (thick arrows) are filling the luminal space. PASpositive elongated spermatids (thin arrows) are seen attached to Sertoli cells. DENA+DOX+MDP group (f) shows STs with a slightly thick PAS-positive BM. PAS-positive elongated spermatids are clearly seen. Scale bar $50 \mu \mathrm{m}$ (a-f) 


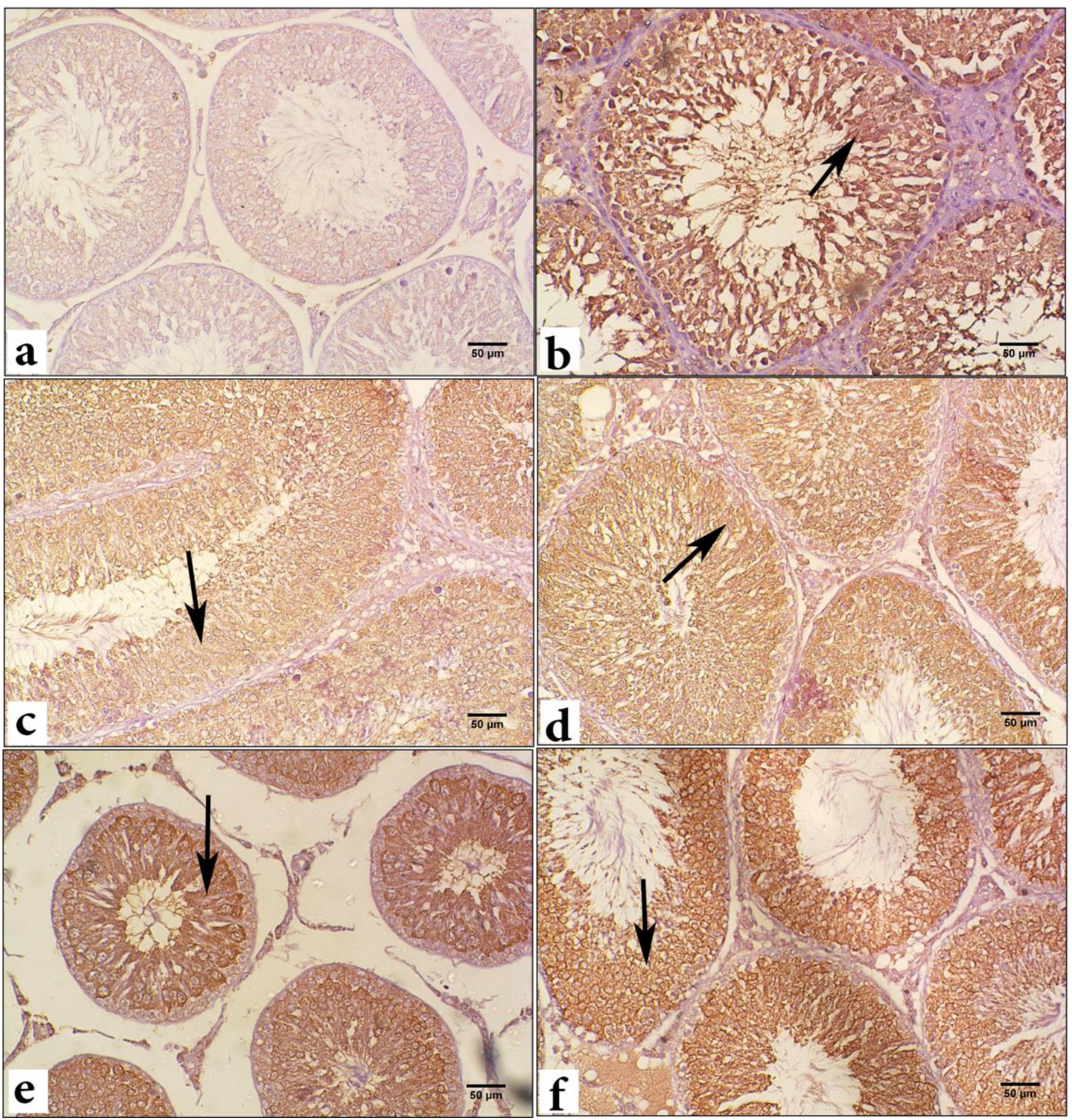

Figure 13. Immune-light micrographs of the caspase-3 immunostained testicular sections. Control group (a) shows almost diffuse negative immunoreaction in STs and interstitial cells of Leydig. DENA alone group (b) shows diffuse strong positive cytoplasmic immunoreactivity (arrow). DENA+ MDP and LAB groups (c and d respectively) show diffuse weak positive cytoplasmic immunoreactivity (arrow). DENA+DOX and DENA+DOX + MDP groups (e and f respectively) show diffuse strong positive cytoplasmic immunoreactivity (arrow) of the different spermatogenic cells and Leydig cells. Scale bar $50 \mu \mathrm{m}$ (a-f)

These histological findings were supported by a significant decrease in the measurements of LCA and LCN when compared to DENA-treated rats with the superiority of LAB treatment. This pointed to a partial anti-proliferative potential of MDP treatment. Noteworthy, these microscopic changes improved testicular weight in both groups with no statistical significance. Also, the serum level of AFP was decreased in both groups with statistical significance in $L A B$ treatment only, in comparison to group 2. In regards to the serum testosterone level, there was a significant increase in both groups in comparison to group 2 with marked elevation in LAB-treated rats indicating a curative effect of both treatments on LCs function. This was reflected in the distribution of LCs in both groups, as shown in $\mathrm{H}$ and $\mathrm{E}$, histomorphometry of LCA \& LCN and the area \% of AR immunoexpression. 


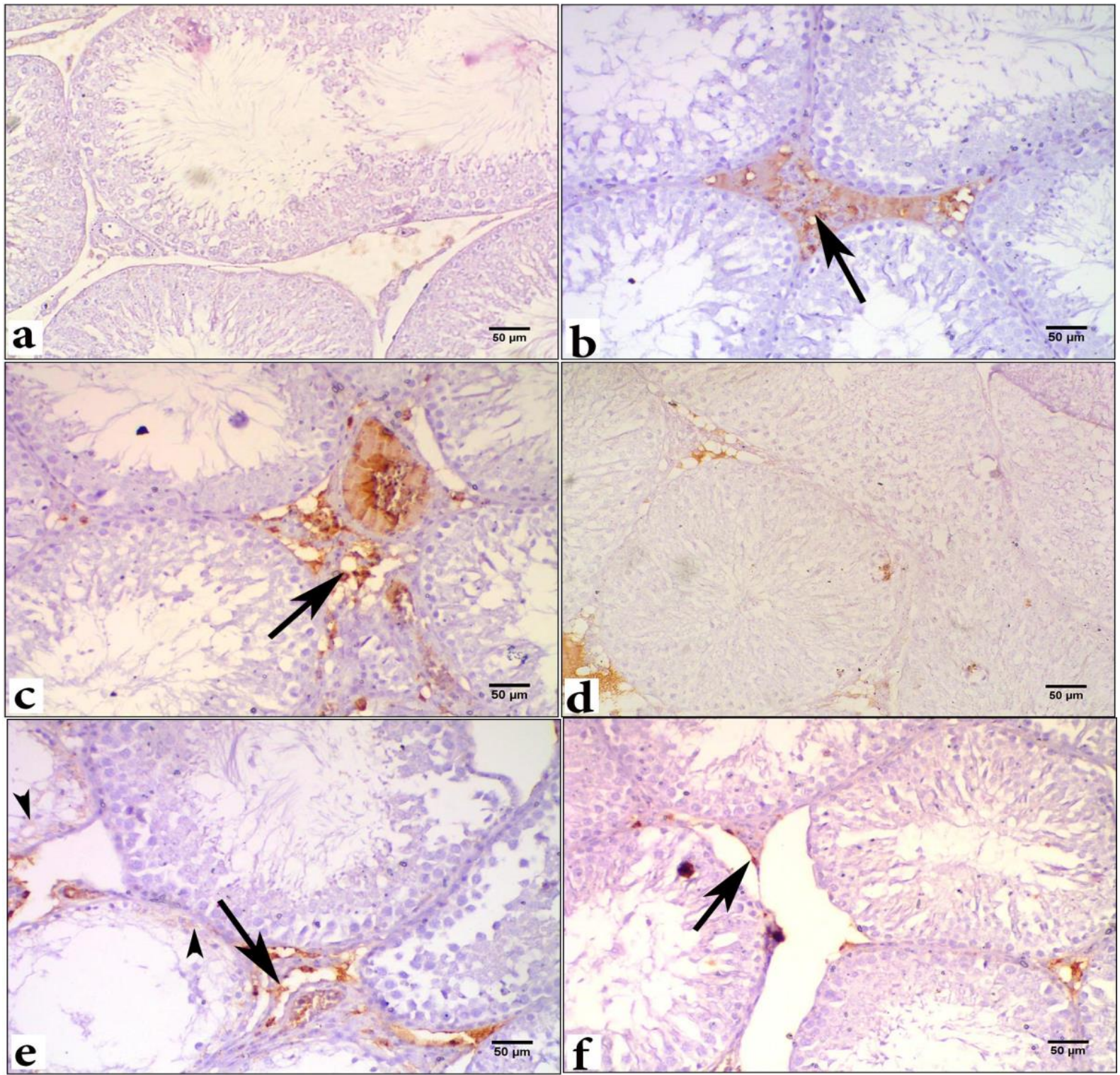

Figure 14. Immune-light micrographs of androgen receptors immunostained testicular sections. Control group (a) shows weak AR immunoreaction. DENA-alone-treated group (b) shows hyperplastic Leydig cells with positive AR immunoreactivity (arrow). DENA+MDP group (c) shows Leydig cell mass with positive AR immunoreactivity (arrow). However, LAB, DOX and DOX+MDP-treated groups (d, e, f) show minimal immunoreaction (arrow). Noteworthy, minimal positively stained cytoplasmic ghosts (arrowheads) of spermatogenic cells are seen in the atrophic depleted STs of DENA + DOX (e). Scale bar $50 \mu \mathrm{m}(\mathrm{a}-\mathrm{f})$

Analysis of serum AMH showed a significant increase in $\mathrm{AMH}$ level in both groups when compared to group 2. Interestingly, the concomitant increase of both serum testosterone and $\mathrm{AMH}$ might refer to a repair of the functional testicular tissue as indicated in the foregoing group. Taking into account the immunohistochemical observations of caspase- 3 immunostaining, there was a significant decrease in the optical density of caspase-3 immunoexpression in both LAB and MDPtreated groups when compared to group 2 . Moreover, when evaluating the oxidant/ antioxidant status using serum biomarkers, there were significant changes. MDP was superior to $L A B$ in reducing $N O$, meanwhile $L A B$ was superior in the restoration of GSHPX. Overall, both MDP and $L A B$ had almost equal antioxidant efficacy. In regards to their effect on TNF, MDP was effective, as an antiinflammatory than LAB treatment. Collectively, different suggestions could be considered plausible mechanisms of protection offered by L. casei and MDP, in alleviating gonadal histology in the current rat model of DENAinduced testicular intoxication. 

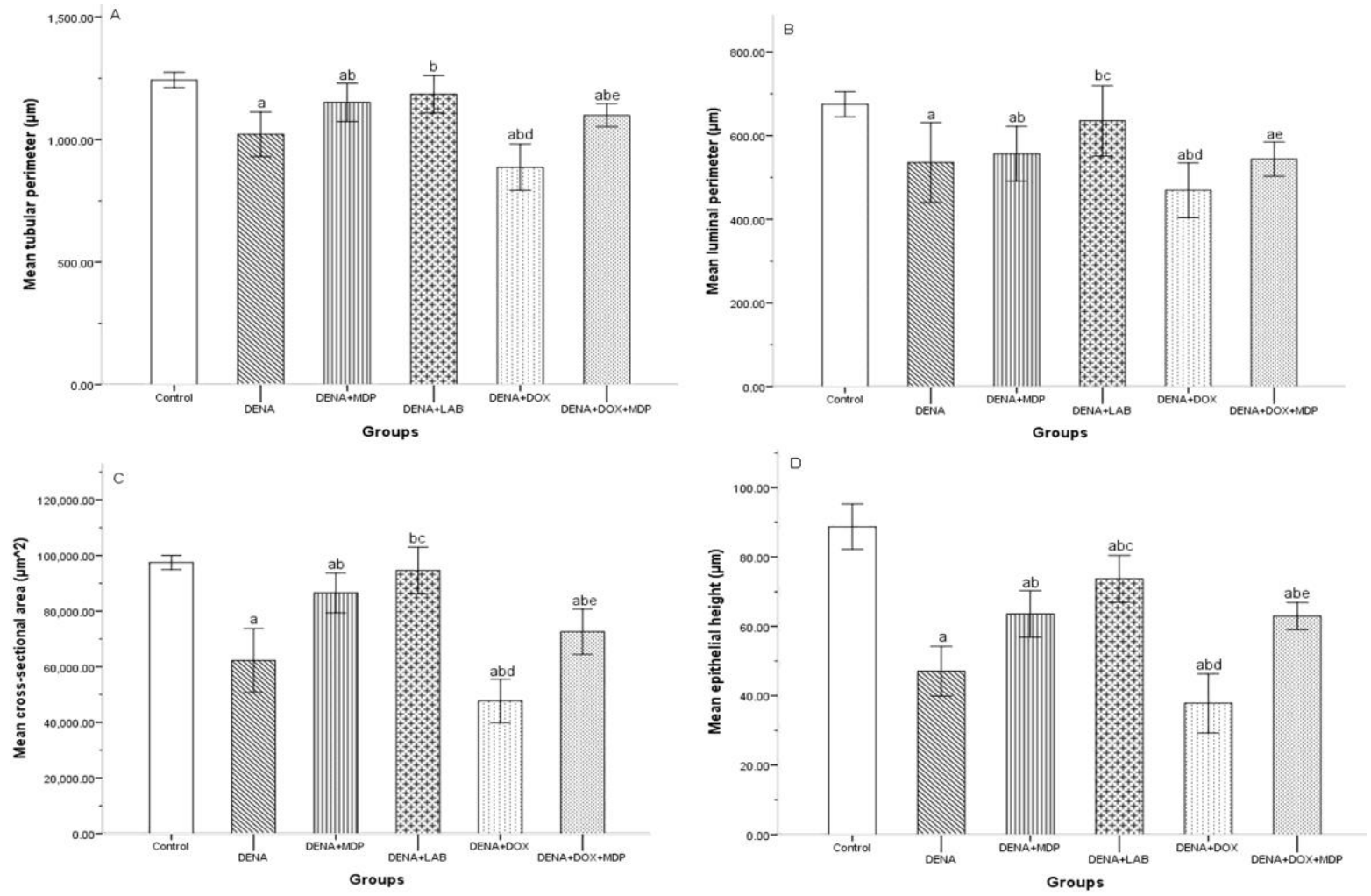

Figure 15. The mean values of the morphometric parameters of the STs of the studied groups (mean $\pm S D, n=10$ ). a:, Significant versus control group. $b$, significant versus DENA group. $c$, significant versus MDP. $d$, significant versus MDP \& LAB. e, significant versus DOX. Post hoc ANOVA was used, $P$-value $<0.05$.
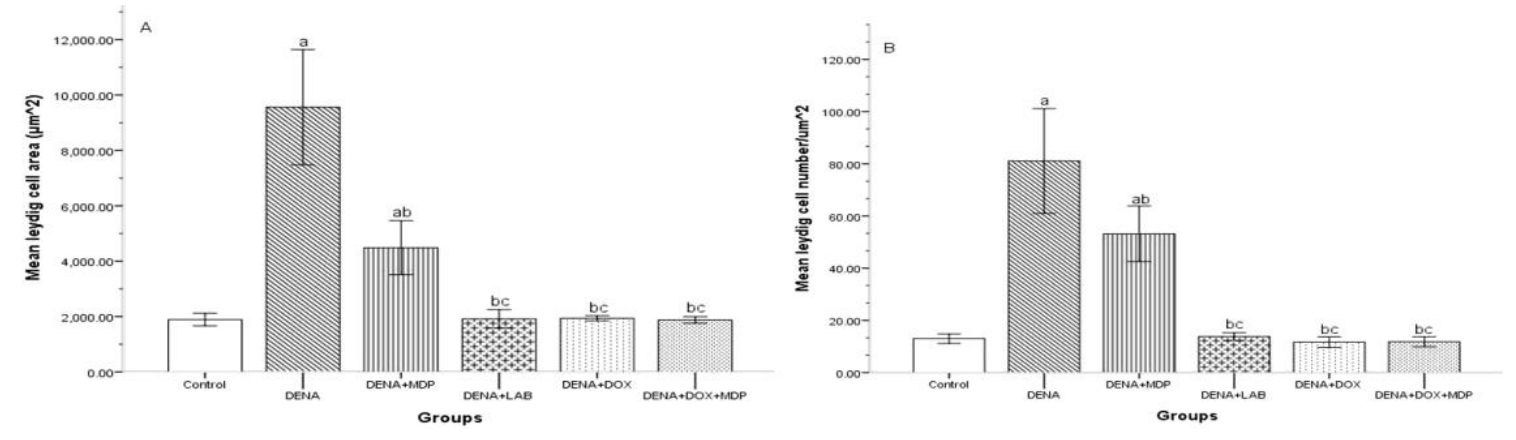

Figure 16. Changes in the mean values of morphometric parameters of Leydig cells in the studied groups (mean $\pm S D, n=10$ ). $A$, significant versus control group. $b$, significant versus DENA group. c:, significant versus MDP. Post hoc ANOVA was used, $P$ value $<0.05$
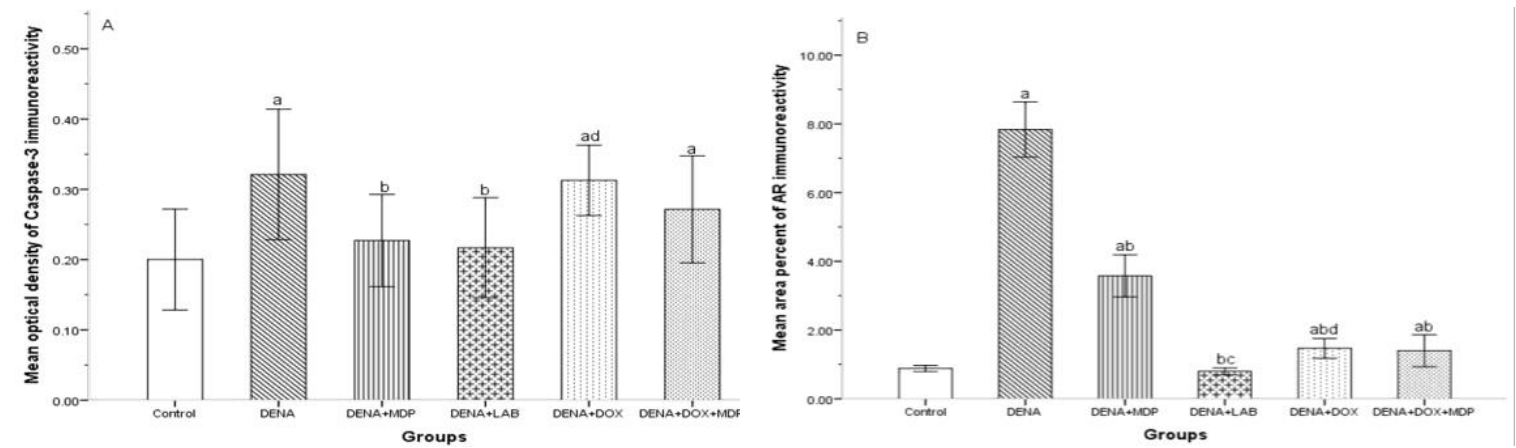

Figure 17. Changes in the mean values of morphometric parameters of the caspase-3 (A) and AR (B)-immunostained STs of the studied groups (mean $\pm S D, n=10$ ). A, significant versus control group. $b$, significant versus DENA group. c:,significant versus MDP. $d$, significant versus MDP and LAB. e, significant versus DOX. Post hoc ANOVA was used, $P$-value $<0.05$. 
Anti-inflammatory, anti-apoptotic, antioxidant and anti-cancer effects were encountered as confirmed by serum TNF, NO, GSH, AFP, H \& E findings and immunohistochemical staining of caspase-3 \& AR immunoreactivity. Moreover, (Delesa, 2017), suggested precise mechanisms for the anticancer activity of LAB. The author reported a cytotoxic effect on cancer cells, immunomodulatory activity on the immune response, stimulatory effect on the release of cytokines such as TNF- $\alpha$, INF- $\gamma$ and other regulatory cytokines and finally, an inhibitory effect on proliferating tumors cells via induction of controlled apoptosis. Regarding MDP, the anti-proliferative potential was slightly limited in testicular tumor despite its potency as in an in vitro anticancer activity (El Malah et al., 2017). In group 5 (DENA+DOX-treated animals), the results showed marked tubular atrophy with a significant decrease of all of the measured tubular morphometric parameters when compared to DENA-alone-treated rats denoting a more toxic effect added to the degenerative changes of STs. However, Leydig cells appeared almost normal. Also, both LCA and LCN were almost normalized when compared to that of the control LC populations, which came in accords with the anticancer effect of DOX as referred in literature (Wakharde et al., 2018). Therefore, the testicular weight loss was more marked than in DENA-only-treated animals.

Also, the serum level of AFP was significantly decreased which runs in line with the antiproliferative effect of DOX (Medeiros et al., 2019). In terms of the serum testosterone, there was a significant increase when compared to group 2, but still significantly less than in groups 3 and 4 . This might indicate a partial alleviative effect of DOX on LCs and testosterone levels with partial interruption of the negative feedback effect on LH. Furthermore, DOX has anti-proliferative activity against rapidly dividing neoplastic cells (Viale et al., 2017). These two reasons could explain the reducing effect of DOX on LCA, LCN, and the extent of the area \% of $A R$ immunoexpression. In addition, DOX produced a partial recovery of the endocrine function of the testis as evident by a synchronous increase in serum levels of $\mathrm{AMH}$ and testosterone. Moreover, the serum biomarkers revealed the worst antioxidant effect but better anti-inflammatory effect than LAB-treated animals. DOX treatment induced a significant decrease in TNF more than MDP and LAB. DOX had minimal effect on GSHPX level while no further significant effect on NO level. Hence, the marked disruption of the tubular histology induced by DOX could be explained by the induction of oxidative stress and acceleration of the apoptotic cascades as confirmed by caspase- 3 immunostaining.

In DENA+DOX+MDP group, the rats showed a partial improvement of the testicular microstructure as evident in $\mathrm{H}$ \& $\mathrm{E}$ and PAS staining. Multiple basal macrovacuoles were observed within tubular epithelium which denoted germ cell loss. The histological observations were supported by the tubular and Leydig cell morphometric measures that showed partial reversal of the tubular measurements and almost normal Leydig cell populations. Evaluation of sperm cell concentration revealed a significant decrease in sperm count when compared to DOX-only treatment (group5).

The concurrent treatment of MDP in group 6 synergized the antioxidant flavor offered by DOX-only treatment however, no further antiinflammatory effect was added. Further improvement in testosterone, $\mathrm{AMH}$, and AFP levels was observed. Also, the caspase- 3 immunostained sections didn't reveal a further improvement in the optical density which runs parallel to the partial improvement in the histological findings. Moreover, no significant difference was observed in the area $\%$ of $A R$ immunoexpression when compared to DOXalone treatment.

\section{CONCLUSION}

In conclusion, six-week-only DENA treatment in rats induced hyperplastic changes in LCs that could be mediated by overexpression of androgen receptors. In addition, the increased Caspase- 3 activities mediated in part, the tubular cytotoxicity observed in the current model of DENA-induced testicular injury. Furthermore, the current work revealed a cytoprotective effect of $L$. casei and MDP on the tubular histoarchitecture that could be related to antioxidant, anti-apoptotic, and anti- 
inflammatory mechanisms. Moreover, an antiproliferative effect was reported in probiotic treatment with moderate potential in MDP. So, probiotics are recommended as a daily nutritional requirement in those at risk and in particular, early-stage cancer patients.

\section{CONFLICT OF INTEREST}

All authors declare no conflicts of interest.

\section{FUNDING}

No fund was received for this work.

\section{AUTHORS' CONTRIBUTION}

Idea and Design of the work: Sahar Ahmed, Rania Abd El-Aal, Neveen Saleh, Tamer El malah, Ahmed Morsi, and Asmaa Elsayed. Performing experiments: Sahar Ahmed, Rania Abd El-Aal, and Neveen Saleh. Analysis and interpretation of data: Ahmed Morsi, Sahar Ahmed, Rania Abd El-Aal, Asmaa Elsayed, Neveen Saleh. Drafting the work: Ahmed Mors, Asmaa Elsyaed, and Tamer El malah. Revision: Asmaa Elsyaed, Tamer El Malah. Final approval: Ahmed Morsi, Sahar Ahmed, Neveen Saleh, Rania Abd El-Aal, Tamer El malah, and Asmaa Elsayed

\section{REFERENCES}

Akingbemi BT, Ge R, Klinefelter GR, Zirkin BR, Hardy MP (2004). Phthalate-induced Leydig cell hyperplasia is associated with multiple endocrine disturbances. The National Academy of Sciences of the USA, 101(3):775-780.

Ali MS, Ahmed S, Uddin F, Matin A, Uddin MS, Yeasmin N (2018). Characterization of Probiotic Properties of Lactic Acid Bacteria Isolated from Yoghurt Available in Bangladesh. Turkish Journal of Agriculture-Food Science and Technology, 6:1544-1549.

Al-Shathly MR, Ali SS, Ayuob NN (2020). Zingiber officinale preserves testicular structure and the expression of androgen receptors and proliferating cell nuclear antigen in diabetic rats. Andrologia, 52(3): e13528.

Bancroft JD \& Lyton C (2018). The Hematoxylins and Eosin. In: Suvarna SK, Bancroft JD, Lyton C (eds) Theory and practice of histological techniques, 8th ed, pp. 126-138.

Bearden H \& Fuquay J (1980). Applied Animal Reproduction. 1st ed. Reston Publishing Company, Inc. Prentice-Hall, Reston, VA, USA.

Bianchi VE (2019). The anti-inflammatory effects of testosterone. Journal of the Endocrine Society, 3:91-107.

De Miguel MP, Gonzalez-Peramato P, Nistal M (2018). Morphological Bases of Human Leydig
Cell Dysfunction. In: Advances in Testosterone Action (Estrada M). IntechOpen publishing, PP.23.

Delesa DA (2017). Overview of Anticancer activity of Lactic Acid bacteria. International Journal of Advanced Research in Biological Sciences, 4:166177.

Ehrmann M, Kurzak P, Bauer J, Vogel R (2002). Characterization of lactobacilli towards their use as probiotic adjuncts in poultry. Journal of applied microbiology, 92: 966-75.

El Malah T, Rashad AE, Shamroukh AH, Ali MM, Mahmoud AE (2017). Synthesis and in vitro Anticancer Evaluation of some Acyclic N- and S nucleosides of Pyridazine Derivatives. Der Pharma Chemica, 9:79-84.

Gronow M (2019). Chemical carcinogenesis. In: Hnilica L S (ed) Chromosomal Nonhistone Protein: Volume I: Biology. CRC Press, pp 93-12.

Hassan H, Ali E, Karim M, Hesari J (2012). Investigation of antibacterial, acid and bile tolerance properties of lactobacilli isolated from Koozeh cheese. in Veterinary Research Forum, 3(3): 181-5.

Herman D, Mantle P (2019). Immunohistochemical Review of Leydig Cell Lesions in Ochratoxin ATreated Fischer Rats and Controls. Toxins (Basel), 11:480.

Inatomi T, Otomaru K (2018). Effect of dietary probiotics on the semen traits and antioxidative activity of male broiler breeders. Scientific Reports 8:1-6.

Johnson-Arbor K, Patel H, Dubey R (2019) Doxorubicin. In: StatPearls [Internet]. StatPearls Publishing; 2020 jan

Kaya E, Ozer Kaya S, Yilmaz S, Ceribasi AO, Turk G (2019). Evaluation of ameliorating effect of lycopene against testicular toxicity due to diethylnitrosamine using biochemical, spermatological and histopathological data. Andrologia, 51:e13274.

Kiernan JA (2015). Immunohistochemistry. In: Kiernan J (ed) Histological and histochemical methods. Theory and practice, 4th ed., Scion Publishing Ltd, pp 454-490.

Li Y, Zhang Y, Yu Q, Meng F (2017). Effect of ligustrazine on a rat model with hepatic preneoplasia. Microbiology, 5:26.

Matuskova Z, Anzenbacher P, Vecera R, Siller M, Tlaskalova-Hogenova $H$, Strojil J, Anzenbacherova E (2017). Effect of Lactobacillus casei on the pharmacokinetics of amiodarone in male Wistar rats. European journal of drug metabolism and pharmacokinetics, 42(1): 29-36.

de Medeiros ASVC, Azevedo ÍM, Celani LMS, Souza TBS, Medeiros AC (2019). Response of $n$ nitrosodiethylamine-induced hepatocellular 
carcinoma to treatment with curcumin vs doxorubicin. Journal of surgical and clinical research, 10: 25-38.

Motawee MM, Saleh NM (2016). Microbiological quality and safety of commercial market yogurt in giza. Journal of Food and Dairy Sciences, 7:1117.

Murray MJ, Huddart RA, Coleman N (2016). The present and future of serum diagnostic tests for testicular germ cell tumours, Nature reviews. Urology, 13:715.

NIH (2011) Guide for the Care and Use of Laboratory Animals. National Academies Press (US)

O'Shaughnessy PJ, Mitchell RT, Monteiro A, O'Hara L, Cruickshanks L, Claahsen-van der Grinten $\mathrm{H}$, Brown P, Abel M, Smith LB (2019). Androgen receptor expression is required to ensure development of adult Leydig cells and to prevent development of steroidogenic cells with adrenal characteristics in the mouse testis. BMC Developmental Biology, 19:1-12.

Popovici L, Amarandi R-M, Mangalagiu II, Mangalagiu V, Danac R (2019). Synthesis, molecular modelling and anticancer evaluation of new pyrrolo [1, 2-b] pyridazine and pyrrolo [2, 1-a] phthalazine derivatives. Journal of enzyme inhibition and medicinal chemistry, 34:230-243.

Pozza C, Pofi R, Tenuta M, Tarsitano MG, Sbardella E, Fattorini G, Cantisani V, Lenzi A, Isidori AM, Gianfrilli D, the testis unit (2019). Clinical presentation, management and follow-up of 83 patients with Leydig cell tumors of the testis: a prospective case-cohort study. Human reproduction, 34:1389-1403.

Rasband WS (2007). ImageJ; US National Institutes of Health: Bethesda, MD, 1997-2007. World Wide Web (http//rsb info nih gov/ij/).

Roy SR, Gadad PC (2016). Effect of $\beta$-asarone on diethylnitrosamine-induced hepatocellular carcinoma in rats. Indian Journal of health sciences and biomedical research, 9:82.

Saadat YR, Khosroushahi AY, Gargari BP (2019). A comprehensive review of anticancer, immunomodulatory and health beneficial effects of the lactic acid bacteria exopolysaccharides. Carbohydrate Polymers, 217:79-89.

Sheweita SA, El Banna YY, Balbaa M, Abdullah IA, Hassan HE (2017). N-nitrosamines induced infertility and hepatotoxicity in male rabbits. Environmental toxicology, 32:2212-2220.

Solano-Gálvez SG, Abadi-Chiriti J, Gutiérrez-Velez L, Rodríguez-Puente $E$, Konstat-Korzenny $E$, Álvarez-Hernández D-A, Franyuti-Kelly G,
Gutiérrez-Kobeh L, Vázquez-López R (2018). Apoptosis: activation and inhibition in health and disease. Medical Sciences, 6 (3): 54.

Steinbach T, Maronpot R, Hardisty J (2015). Human relevance of rodent Leydig cell tumors. Hamilt Hardy's Ind Toxicol New York John Wiley Sons 1189-1196.

Tambekar D, Bhutada S (2010). An evaluation of probiotic potential of Lactobacillus sp. from milk of domestic animals and commercial available probiotic preparations in prevention of enteric bacterial infections. Recent research in science and technology, 2:82-88.

Thompson LA and Darwish WS (2019). Environmental chemical contaminants in food. review of a global problem. Journal of toxicology, 2345283, PP.1-14.

Tolba R, Kraus T, Liedtke C, Schwarz M, Weiskirchen $R$ (2015). Diethylnitrosamine (DEN)-induced carcinogenic liver injury in mice. Laboratory animals, 49:59-69.

Tutun H, Özmen Ö, Aktaş I, Yalçin A, Türk A (2019). Investigation of the effects of artemisinin on testis and kidney injury induced by doxorubicin. Acta Veterinaria, 69(2): 177-191.

Viale $\mathrm{M}$, Giglio V, Monticone M, Monticone M, Maric I, Lentini G, Rocco M, Vecchio G (2017). New doxorubicin nanocarriers based on cyclodextrins. Investigational new drugs, 35:539-544.

Wakharde AA, Awad AH, Bhagat A, Karuppayil SM (2018). Synergistic activation of doxorubicin against cancer: a review. American Journal of Clinical Microbiology and Antimicrobials, 1:1-6.

WHO N (2002). Concise International Chemical Assessment Document; 38. World Heal Organ Geneva, 52.

Xu H-Y, Zhang H-X, Xiao Z, Qiao J, Li R ( 2019). Regulation of anti-Müllerian hormone $(A M H)$ in males and the associations of serum $\mathrm{AMH}$ with the disorders of male fertility. Asian journal of andrology, 21:109.

Zhang Y, Piao Y, Li Y, Song M, Tang P, Li C (2013). 4Nitrophenol induces Leydig cells hyperplasia, which may contribute to the differential modulation of the androgen receptor and estrogen receptor- $\alpha$ and- $\beta$ expression in male rat testes. Toxicology letter, 223:228-235.

Zhu J, Luan Y, Li H (2018). Management of testicular Leydig cell tumor: A case report. Medicine(Baltimore), 97:e11158-e11158.

Zirkin BR, Papadopoulos V (2018). Leydig cells: formation, function, and regulation. Biology Reproduction, 99:101-111. 